\title{
دراسة إقتصادية لآداء القطاع الزراعي المصري في ظل التحديات المعاصرة
}

\author{
فاطمة الزهر اءع احمد جبريل \\ معهد بحوث الاقتصاد الزر اعي- مركز البحوث الزر اعية \\ الملخص
}

تتمنل مشكلة البحث فيما يعكسه الو اقع من تر اجع و اضح في مؤثر ات النثاط الإقتصادي بالقطاع الزر اعي، فقد إنخفضت نسبة مســاهمته

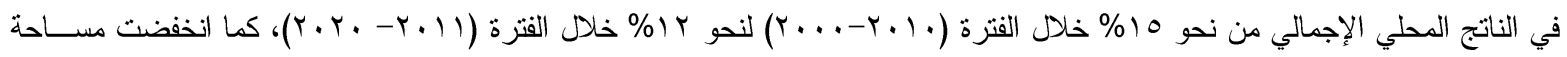

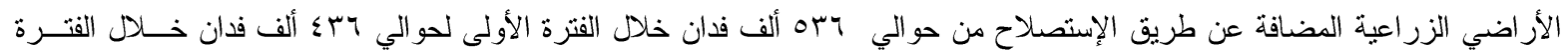

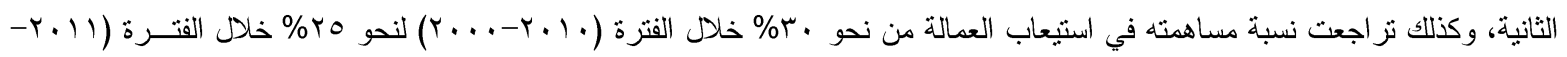
9 ( ـ r)، مما ينطلب الوقوف على التحديات التي تو اجه القطاع الزر اعي للتوصل للمقترحات والحلول التي من شأنها تمكينه من أداء دوره.

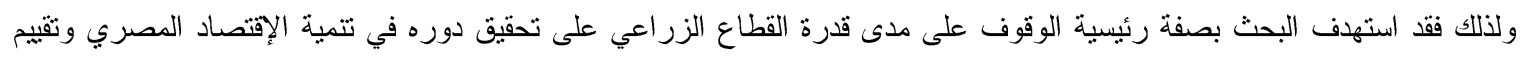

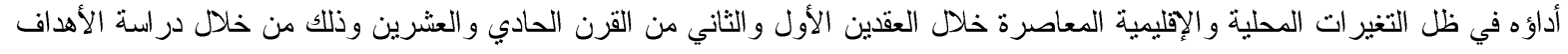

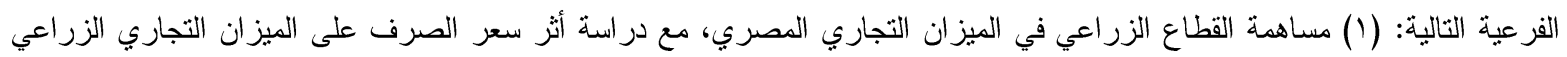

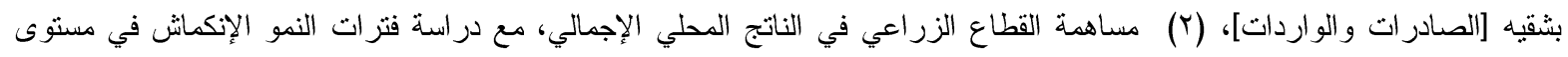

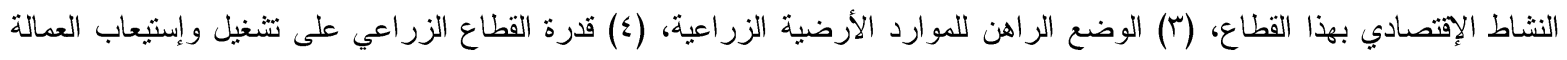

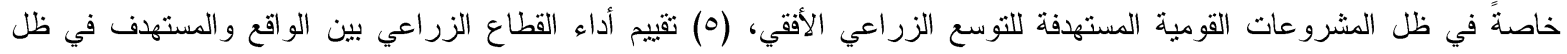

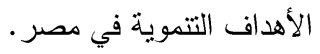
وقد توصل البحث لمجموعة من النتائج من أهها: أن القطاع الزراعي ساهم في تخفيف العبء الإقتصادي على المقتصد المصري خلال

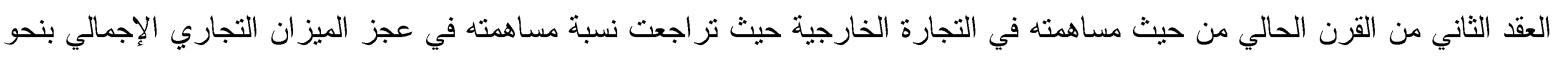

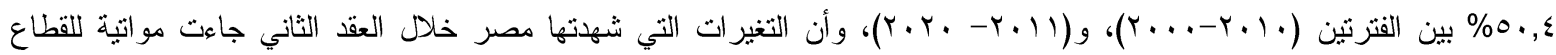

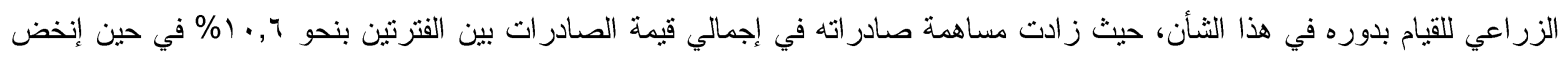

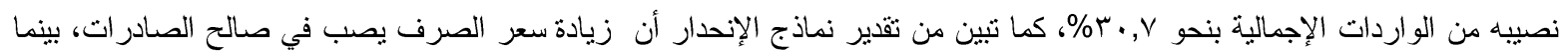

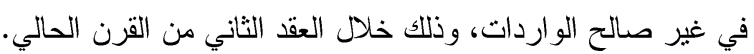

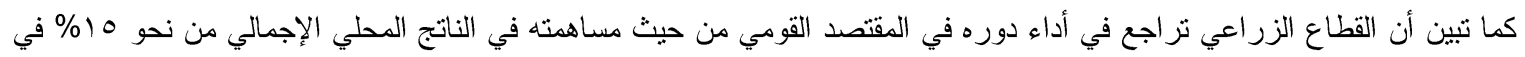

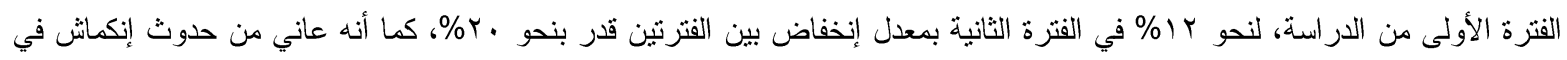

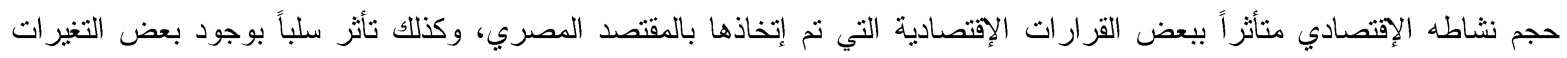

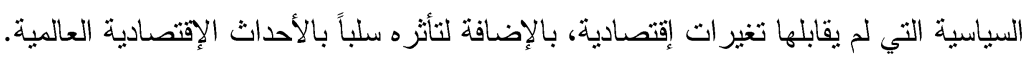

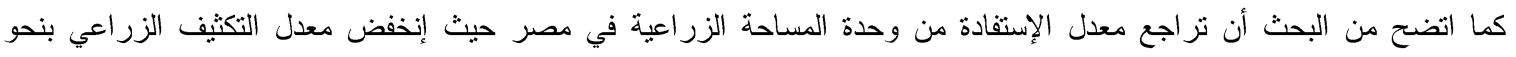

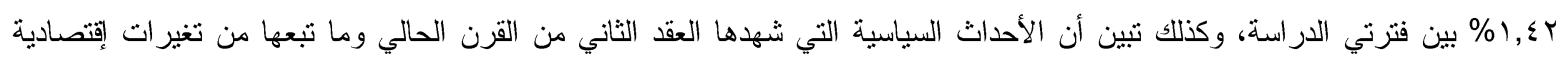

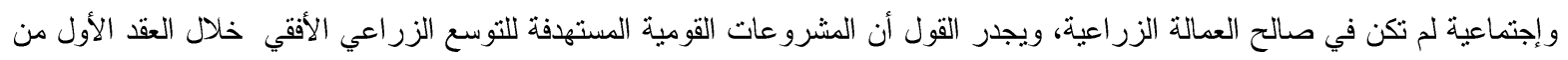

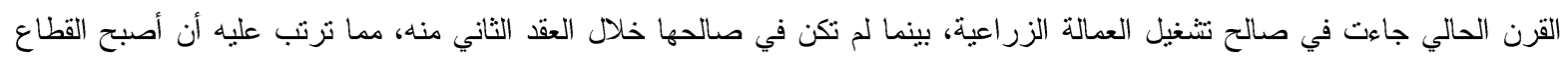

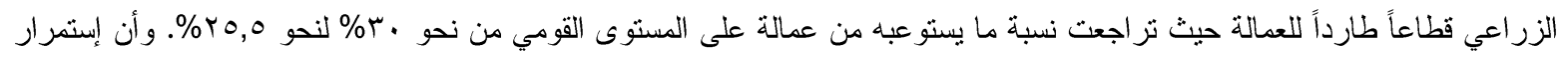

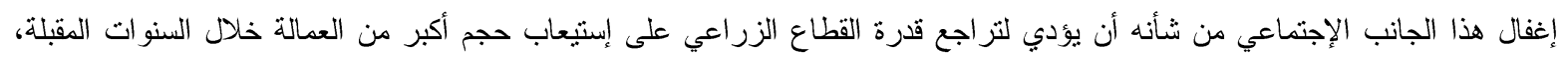

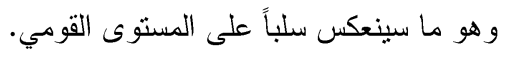

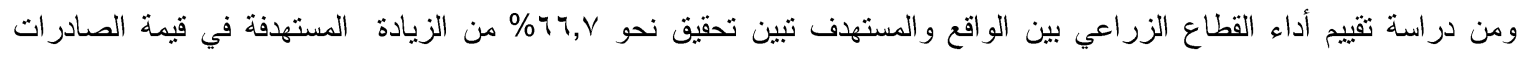

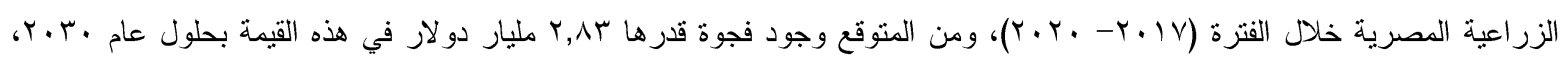

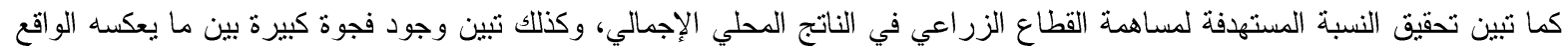

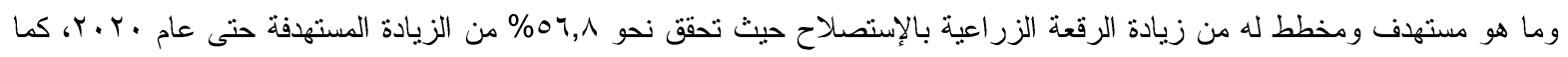




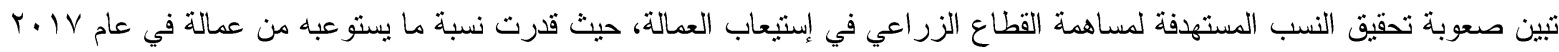

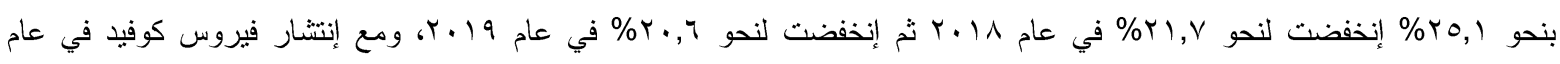

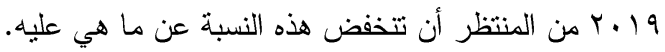

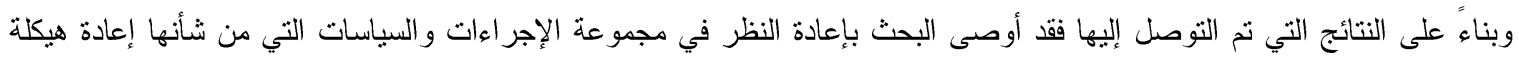

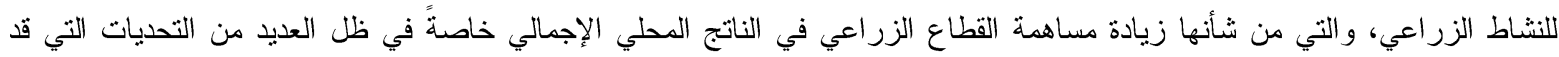

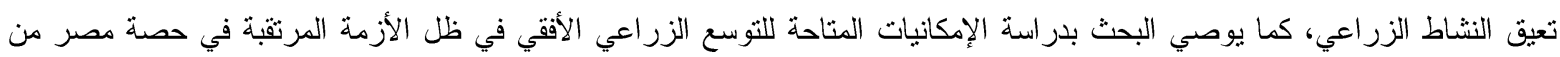

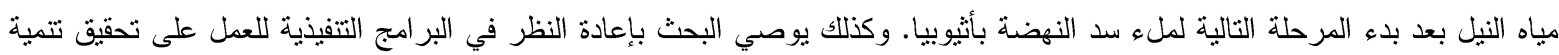

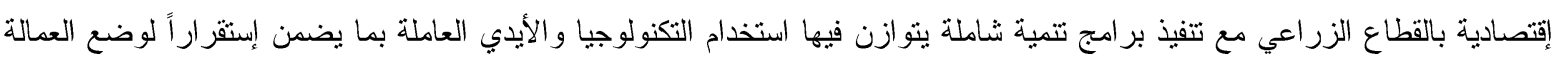
الزر اعية و الإستفادة منها خاصةً العمالة الماهرة منها، و العمل على عرقلة العو امل المنبطة لنحقيق الأهداف المنثودة من القطاع الزراعي.

الكلمات المفتاحية: أداء القطاع الزراعى، عمالة زراعية، موارد أرضية، استصلاح اراضى، ناتج محلى زراعى.

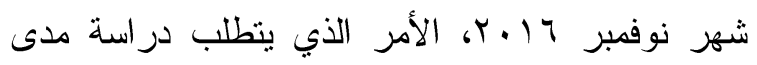
المقدمة

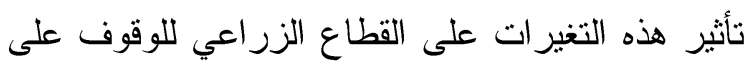

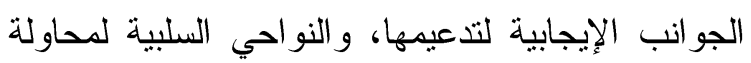
تفاديها خلال السنوات القادمة.

\section{المشكلة البحثية}

يعكس الو اقع تر اجعاً و اضحاً وجلياً فــي مؤشـــرات النشاط الإقتصادي بالقطاع الزر اعي، فقد إنخفضت ولن نسبة

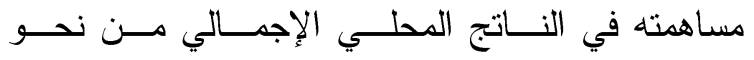

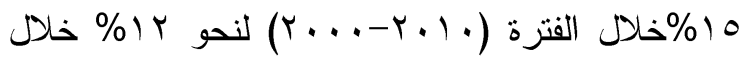
الفترة (1) الأر اضي الزر اعية المضافة عن طريق الإستصداح من

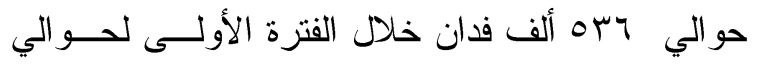
جسع ألف فدان خلال الفترة الثانية(')، وكذلك تز اجعت

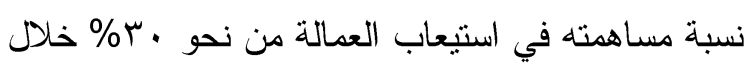

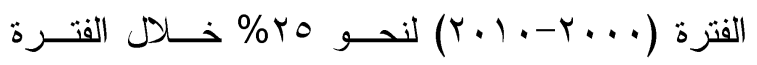

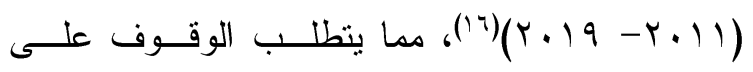

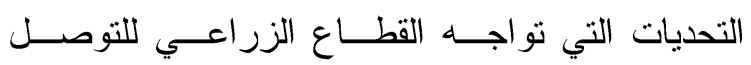

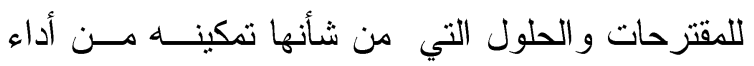

\section{أهداف البحث}

في ضوء مشكلة البحث فقد استهدف هذا البحث بصفة رئيسية الوقوف على مدى قدرة القطاع الزراعي على تحقيق دوره في تتمية الإقتصاد المصري وتقييم أداؤه في ظل التغيرات المحلية والإقليمية المعاصرة لإنها

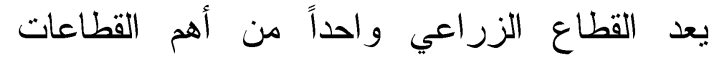

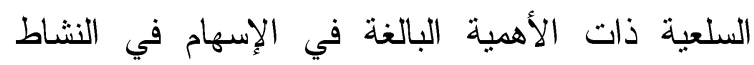

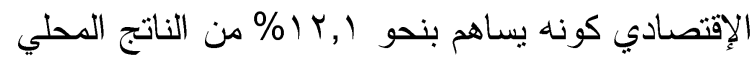

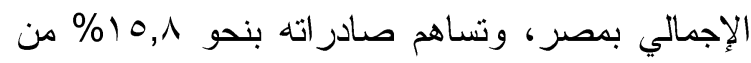

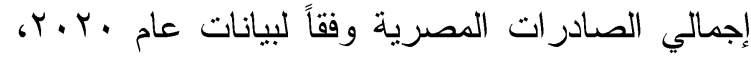
كما بسنوعب نحو 7,_r\% من الأيدي العاملة وفقاً

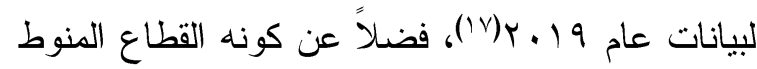
به تحقيق الأمن الغذائي بمصر، ويعد قطاعاً يعول عليه

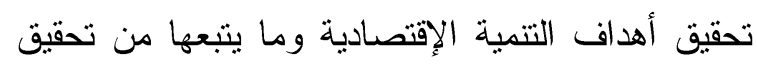
نمو إقتصادي.

وقد شهدت الساحة المحلية والإقليمية خلال العقدين

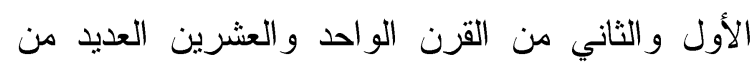

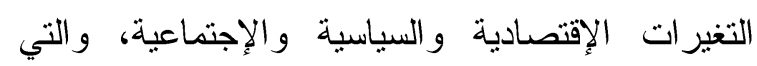

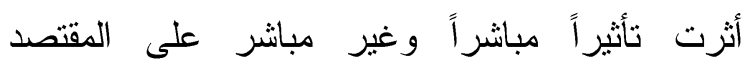
المصري ومن ثم القطاع الزر اعي، ومن تلك التغيرات

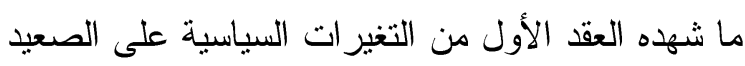

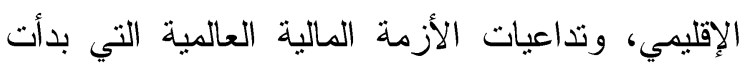

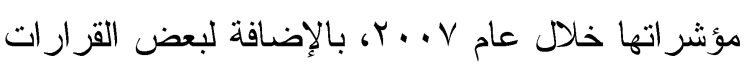

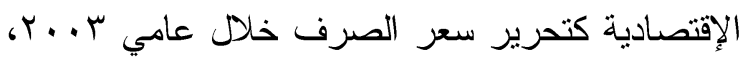

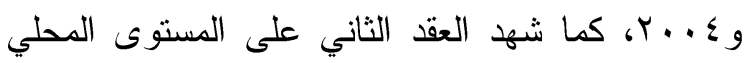

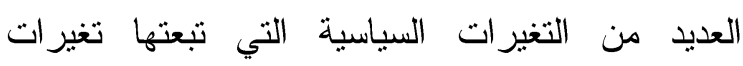
إقتصادية وأخرى هيكلية في العديد من القطاعات الإقتصادية بمصر، وصدور حزم عديدة من القزارات

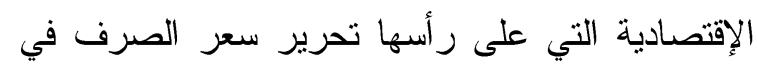


تم استخدام الأسلوب ذاته لبو اقى نماذج الإنحدار المقدرة

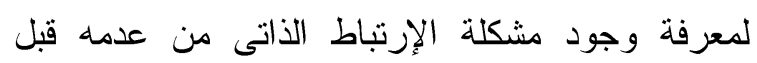

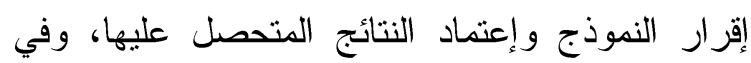
هذا الإطار تم استبعاد عدد من النماذج لوجود هذه المشكلات مع عدم امكانية حلها. وكذلك نم تقدير القيم القيم الحقيقية لبعض متغير اتلهات

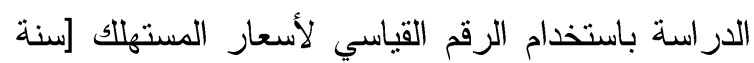

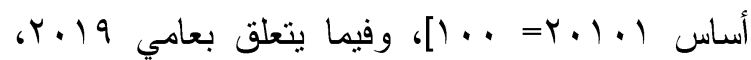

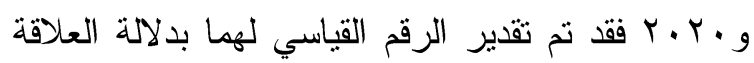

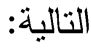

معدل التضخم = [الرقم القياسي في العام الحالي الرقم القياسي في العام السابق] / الرقم القياسي في العام

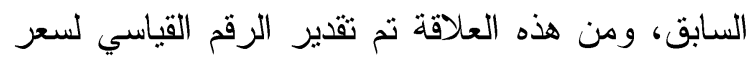
المستهلك في العام الحالي. وقد اعتمد البحث على البيانات الثانوية المنشورة في

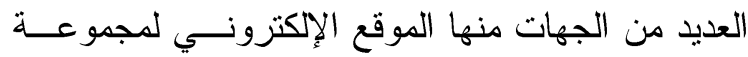

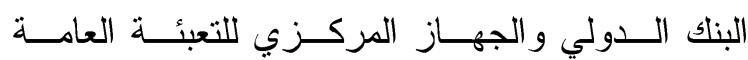

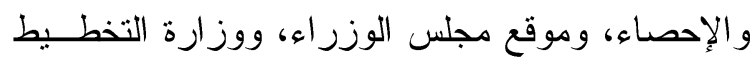
و التتمية الإقتصادية.

\section{النتائج البحثية}

أولاً: تقييم أداء القطاع الزراعي من حيث المساهمة في التجارة الخارجية

يتتاول هذا الجزء من البحث دور القطاع الزراعي في مساهمته في مجال التجارة الخارجية، وتقييم أداؤه

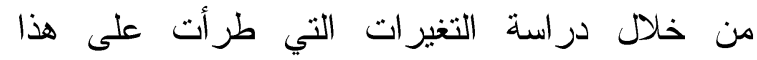

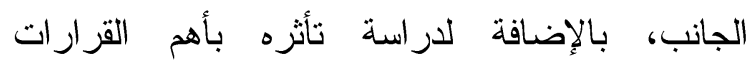
الإقتصادية خلا العقدين الأول والثاني من القرنه باتهن باهن الواحد و العشرين، وفيما يلي إستعر اضاً لأهم النتائج

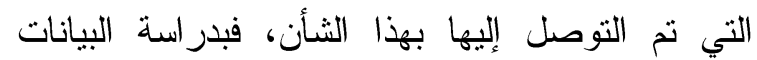

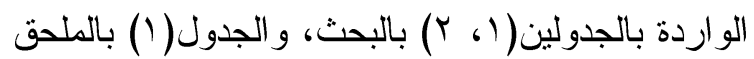

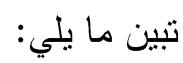

خلال العقدين الأول و الثاني من القرن الحادي و العشرين وذلك من خلال دراسة الأهداف الفرعية

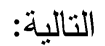
(1) مساهمة القطاع الزراعي في الميزان التجاري

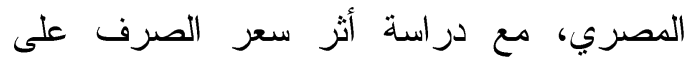
الميزان التجاري الزراعي بشقيه الصنادرات

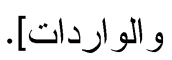

(Y) مساهمة القطاع الزراعي في الناتج المحلي الإجمالي، مع دراسة فترات النمو الإنكماش في لئي مستوى النشاط الإقتصادي بهذا القطاع. (r)(الوضع الراهن للمو ارد الأرضية الزراعية.

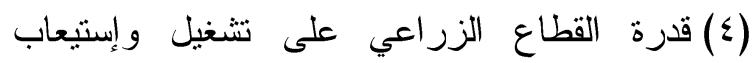
العمالة خاصةً في ظل الترة المشروعات القومية المستهدفة للتوسع الزر اعي الأفقي.

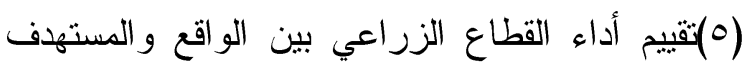
في ظل الأهداف التتموية في مصر. الأسلوب البحثي ومصادر البيانات

اعتمد البحث تحقيق أهدافه على كل من: التحليل الوصفي، و التحليل الإحصائي القياسي، حيث تم تقسيم

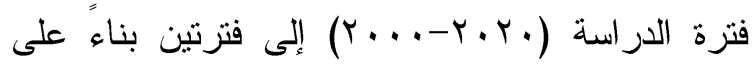
اختبار (F) لوجود فرق معنوي بين الفترتين، بحيث

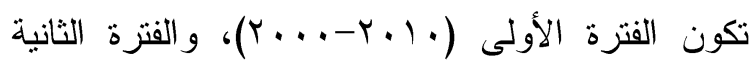

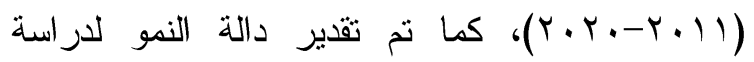
معدلات التغير في متغير ات البحث، كما نم تقدير التغير لفرير النسبي بين متوسطات الفترتين، وكذلك التغير النسبي بين السنوات وبعضها واستخدام دلالاته بما يتفق مع ولعين موضوع البحث. كما نم استخدام نماذج الإنحدار البسيط بتقدير دالة القوى وكتابتها في صورتها الخطية [اللوغاريتمية المزدوجة]، وذللك بعد التأكد من سكون البيانات

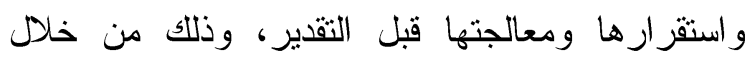
التوقيع البيانى لمعاملات الإرتباط للمتغيرات موضع ونع

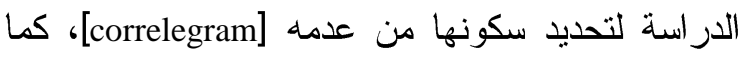




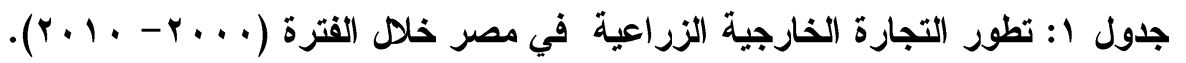

\begin{tabular}{|c|c|c|c|c|c|c|c|c|c|c|c|c|c|}
\hline \multicolumn{4}{|c|}{ العجز في الميزان التجاري الزراعي } & \multicolumn{4}{|c|}{ الواردات الزراعية } & \multicolumn{3}{|c|}{ الصادرات الزراعية } & \multicolumn{2}{|c|}{ حجم التجارة الخارجية الزراعية } & \multirow{3}{*}{ السنة } \\
\hline 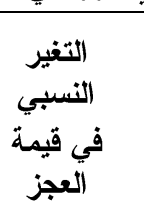 & 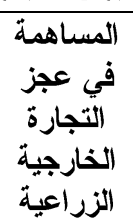 & القيمة & التئ قيمة التببي & في الجماهمة & التي حجاهمة & القيمة & النسبيميَ في & في الجمالمة & التي حجاهمة & القيمة & الجمالي حجمة التخارة & الزجأجأية & \\
\hline$\%$ & $\%$ & منيار & $\%$ & $\%$ & $\%$ & مليار & $\%$ & $\%$ & $\%$ & منيار & $\%$ & منيار & \\
\hline- & $1 \leqslant, Y_{O}$ & $\varepsilon, 4$. & - & $1 \%, 1 \leq$ & $Y \wedge, Y Y$ & 7,19 & - & $1 ., 90$ & $r, \wedge \wedge$ & 1,1 & $1 r, 09$ & $\Lambda, \backslash \wedge$ & $r \ldots$ \\
\hline$I V, A Y$ & $10, \wedge \mathrm{V}$ & $0, \leqslant Y$ & $\mid r, q 1$ & $1 \leqslant, Y_{T}$ & $\lambda ., .0$ & $V, r r$ & .07 & $1 \cdot, 94$ & 19,90 & 1,1 & $1 \pi, \leqslant \leqslant$ & $9, \cdot r$ & $r \ldots l$ \\
\hline $9, \lambda \vee$ & $17, \wedge 7$ & 0,97 & rl, ro & $10,0$. & Vo, VV & $\Lambda, \vee \uparrow$ & 00,07 & $1 T, r \varepsilon$ & $r \leqslant, r T$ & $r, \Lambda$ & $1 \leqslant, \wedge 9$ & 11,09 & $r \ldots r$ \\
\hline$r, \cdot r-$ & $r \cdot, T \varepsilon$ & $0, \wedge \varepsilon$ & $1 \%, \leqslant 7$ & $10, Y V$ & $\vee \cdot, \vee q$ & $9,9 \leqslant$ & $\leqslant T, \varepsilon r$ & $11,1 \varepsilon$ & $\langle q, r)$ & $\varepsilon, 1$ & $1 T, \mathrm{VV}$ & $1 \leqslant, \cdot \varepsilon$ & $r \ldots r$ \\
\hline$r_{\Lambda}, \cdot \tau_{-}$ & $11, Y \wedge$ & זT, & $0, r \leqslant-$ & $|1, \wedge|$ & $r 1, \wedge \Lambda$ & $q, \varepsilon r$ & $\leqslant 1, \leqslant 4$ & $1 T, 17$ & $r \Lambda, ו r$ & 0,1 & $11,9 \leqslant$ & $10, Y_{Y}$ & $r \ldots \varepsilon$ \\
\hline $1.9,1$. & $1 \leqslant, r_{0}$ & $V, 04$ & $\leq 4,1 \leq$ & $i_{,},$. & $7 \curlywedge, 9 \leq$ & $1 r, V_{4}$ & 7,9 . & $1 ., .4$ & $\mu_{1, .7}$ & $7, Y$ & $11, r \mathrm{r}$ & 19,97 & r... \\
\hline $0, r \varepsilon$ & $r \cdot, 17$ & $v, 97$ & $7,01-$ & $1 \cdot, \lambda V$ & $V Y, \leqslant 1$ & Ir,AT & $r \cdot, q V_{-}$ & $r, Y_{1}$ & $r Y, 0 q$ & $\varepsilon, 9$ & $9, .1$ & IV,VT & $r \ldots r$ \\
\hline$r \leq, 00$ & $17,1 \mathrm{~V}$ & 9,94 & $19, \wedge \varepsilon$ & $1 ., 1$. & $v r, v)$ & $10, \leqslant r$ & $|r,| \Lambda$ & $Y, \cdot Y$ & $r \uparrow, r_{q}$ & 0,0 & $\wedge, 0 \wedge$ & $r \cdot, 9)$ & $r \ldots r$ \\
\hline$q 1, \cdot r-$ & זT, & $\cdot, \wedge 9$ & $r r, 01-$ & $\varepsilon, 1$. & 01,97 & $11, \times 9$ & $q \Lambda, \uparrow q$ & $V, T Y$ & $\varepsilon \wedge, \cdot \varepsilon$ & $1 \cdot, 9$ & $0, Y V$ & $r, T, T q$ & $r \ldots \lambda$ \\
\hline |rsr,r| & $11, \leqslant 7$ & IT,YY & $M \varepsilon, \cdot T$ & $1,0 \mathrm{OV}$ & רו, & Y $\Psi, \varepsilon Y$ & $r, 1$. & $9, \wedge 1$ & צr, & $1 r, r$ & $1 \cdot, r$. & rq, ז & $r \ldots q$ \\
\hline 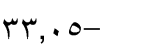 & $7, \cdot 1$ & $\wedge, \wedge 0$ & $\cdot, Y_{4-}$ & $\Lambda, \mathrm{V} \vee$ & $7 ., .9$ & r५, ro & rr,ON & $11, r$. & $r q, 9)$ & $Y \gamma, 0$ & $9, \pi$ & $\leqslant r, \wedge 0$ & $r \cdot 1$. \\
\hline- & $1 \cdot$, or & $7, Y 1$ & - & $1 \cdot, 94$ & $T \Lambda, 7 \pi$ & $1 r, \leqslant \wedge$ & - & 9,74 & $r q, \wedge \wedge$ & $T, V Y$ & $1 \cdot, 7$ & $r \cdot, Y_{T}$ & المنوسط السنوي * \\
\hline- & 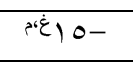 & 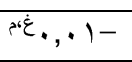 & - & $\wedge, \varepsilon-$ & - & "Ir & - & $0 . \mathrm{V}-$ & & "r) & $p \cdot \dot{\varepsilon}_{1, \Lambda-}$ & $" 1 \leq \leqslant, 9$ & معدل التغير (\%) \\
\hline
\end{tabular}




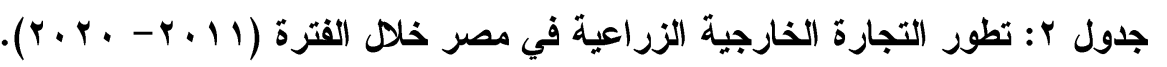

\begin{tabular}{|c|c|c|c|c|c|c|c|c|c|c|c|c|c|}
\hline \multicolumn{3}{|c|}{ العجز في الميزان التجاري الزراعي } & \multicolumn{4}{|c|}{ الواردات الززراعية } & \multicolumn{4}{|c|}{ الصادرات الزراعية } & \multicolumn{2}{|c|}{ حجم التجارة الخارجية الزراعية } & \multirow{3}{*}{ لسنة } \\
\hline النسبيّة في & الخزا التجارة فية & القيمة & النسبي فيزي & فالمي إجمالية & التي حجاهمة & القيمة & النسبي فئي & التي إجمالية & التي التجاهمة & القيمة & إلجمالي حجاهمة في & إلجمالي حجارة & \\
\hline$\%$ & $\%$ & منيار & $\%$ & $\%$ & $\%$ & منيار & $\%$ & $\%$ & $\%$ & منيه & $\%$ & منيه & \\
\hline 04,91 & $11,7 \mathrm{~V}$ & $r, r r$ & 07,91 & $11,1 \varepsilon$ & $T V, \varepsilon)$ & $\varepsilon, \mu v$ & $1 \leqslant, r_{9}$ & $1 \cdot, \pi$ & $r r, 09$ & $r \cdot, \cdot \cdot$ & $1 \cdot, 97$ & $71, \mathrm{TV}$ & $r .11$ \\
\hline 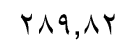 & $\mid \varepsilon, \varepsilon 1$ & Mч,V५ & $r \wedge q, \wedge r$ & Ir,Ir & $\vee ৭, \wedge q$ & Or,07 & $r Y \leqslant, Y_{0}$ & $\wedge, \wedge \circ$ & $r r, 11$ & 10,1 & $11,1 \mathrm{~V}$ & $\because \wedge, r \uparrow$ & $r \cdot I r$ \\
\hline $1 v, 00$ & $11, r$. & $r \lambda, q r$ & $1 v, 00$ & 1,14 & $\mathrm{VI,IV}$ & $\varepsilon \Lambda, T r$ & $1,0 .-$ & 9.97 & $r \wedge, \wedge r$ & $19, \mathrm{~V}$ & $1 \cdot, \leqslant 0$ & u, rr & $r \cdot I r$ \\
\hline$\{0, \varepsilon \wedge-$ & $r, 00$ & ᄉ, ro & $\leq 0, \varepsilon \wedge-$ & $0, \xi \vee$ & Oᄉ,Or & $r \lambda, T_{0}$ & $\curlyvee \wedge, \leqslant \wedge$ & $1 \cdot, \varepsilon$. & $\varepsilon 1, \leqslant V$ & $r \cdot, r$ & $\Upsilon, \wedge)$ & $\{\wedge, 90$ & $r \cdot 1 \varepsilon$ \\
\hline rr,or- & $r, \leq \varepsilon$ & $9, \wedge \wedge$ & $r Y, O r-$ & $0, r \varepsilon$ & $\Delta ৭, \vee 1$ & $r \cdot, \mu$ & $\varepsilon, .4$ & $1 Y, 04$ & $\varepsilon \cdot, r q$ & $r \cdot, 0$ & 7,90 & $0, \wedge \wedge$ & $r \cdot 10$ \\
\hline$r v, 99$ & $r, Y \leqslant$ & $i r, \cdot v$ & $r V, 99$ & 0,11 & $\because, \wedge \varepsilon$ & $\mathrm{M} 4,7 \mathrm{~V}$ & $17, Y_{4}$ & $1 ., r_{0}$ & $r 9,17$ & $r r, r$ & $T, \leqslant Y$ & T.,TY & $r .17$ \\
\hline $11 v, \leqslant 9$ & $r, 1$. & $r r, \varepsilon V$ & $118, \leqslant 9$ & $0,0 \mathrm{~V}$ & $T ., Y_{0}$ & $T Y, \cdot V$ & $\| r, r \mu$ & $9, \leqslant 0$ & $r q, v_{0}$ & $\varepsilon r, \uparrow$ & 7,70 & $1.9,7 \mathrm{~V}$ & $r \cdot 1 V$ \\
\hline $1 \leqslant \leqslant, \wedge 9$ & $\varepsilon, 1 V$ & $r \Lambda, r)$ & $1 \leqslant \leqslant, \wedge 9$ & $7, Y \leqslant$ & $T r, 01$ & $\wedge 9, \wedge 1$ & $11 \wedge, 7 \leqslant$ & $9, \wedge \curlywedge$ & $r q, \leqslant 9$ & 01,7 & $V, r)$ & $\mid \leqslant 1, \leqslant 1$ & $r \cdot 1 \Lambda$ \\
\hline$\varepsilon \varepsilon, Y$. & 0,7 & $\varepsilon 1,01$ & $\varepsilon \varepsilon, r$. & $\gamma, \gamma$. & $7 r, 90$ & $90, Y \wedge$ & $r r, I V$ & $1 \cdot, 10$ & r.,. & or,v & $\Lambda, \uparrow$ & $1 \leqslant \wedge, 9 \wedge$ & $r .19$ \\
\hline $19,70-$ & $7,7 \leqslant$ & ro,. T & $19,70-$ & $1 \cdot, 0$. & $7 ., 01$ & VY, 17 & $\Lambda, \vee Y-$ & $10, Y 1$ & $r q, \leqslant q$ & $\varepsilon \vee, 1$ & 11,97 & $119, r_{7}$ & r.r. \\
\hline- & $0, r^{\mu}$ & $r \xi, 0 V$ & - & $Y, 04$ & $T \leqslant, .0$ & 04,07 & - & $1 \cdot, 71$ & ro,rr & $r 1,09$ & $\Lambda, \sum \wedge$ & $\Lambda V, Y O$ & المتوسط السنوي \\
\hline- & ríq, $\vee-$ & ( & - & - & - & 9 & - & 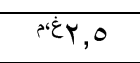 & - & $" 1 \varepsilon$ & $v, O-$ & ${ }^{* *} 1 \cdot, \mathrm{V}$ & معدل التغير (\%) \\
\hline
\end{tabular}

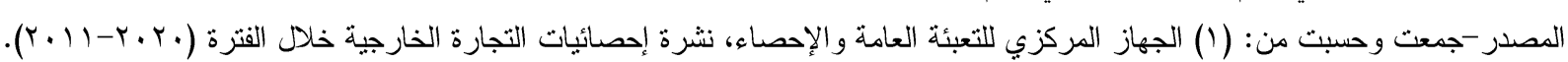

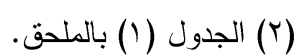


الدراسة قدرت بنحو IV,AV\%، ومن جهةٍ أخرى تنبين

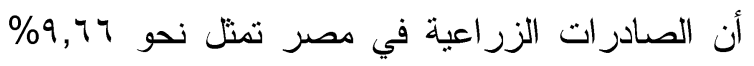

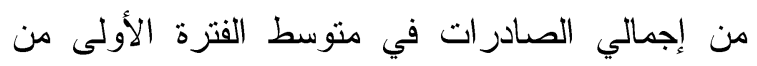
الدراسة، ثم زادت قدرة القطاع الزر اعي في مساهمته

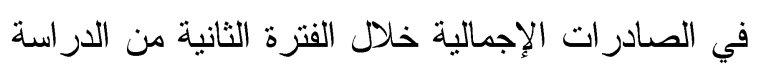
بنحو 09, • 1\%، حيث بلغت نسبة مساهمته خلال هذه

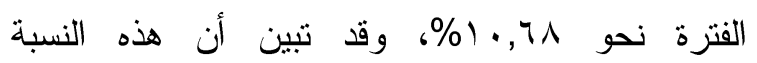

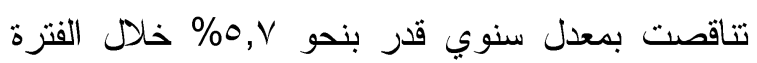

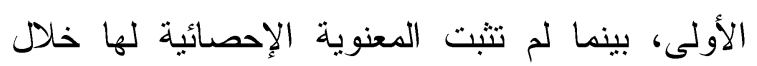
الفترة الثانية من الار اسة، (r) بدراسة قيمة الواردات الزراعية خلال فترني

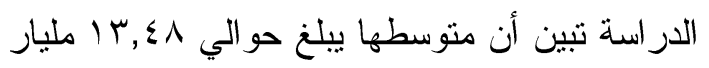

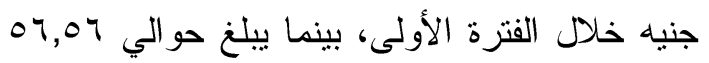

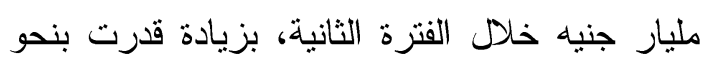

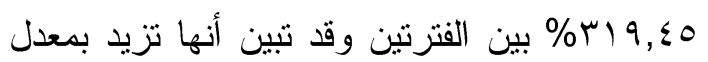
سنوي قدر بنحو r r\% خلد الفترة الأولى، ونحو 9 هلال الفتزة الثانية. كما تبين أن الواردات الزراعية نساهم بنحو

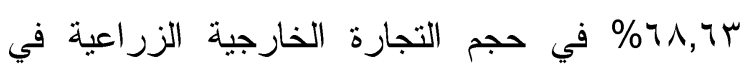
متوسط الفترة الأولي، انخفضت هذه النسبة لتساهم بنحو

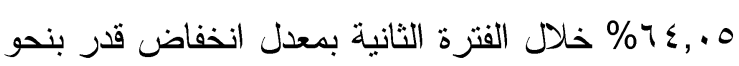

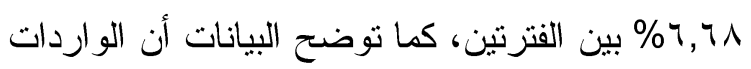

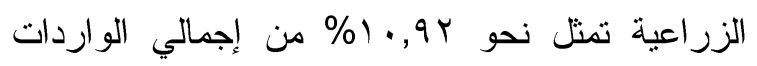

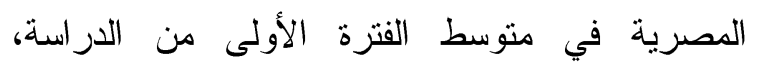

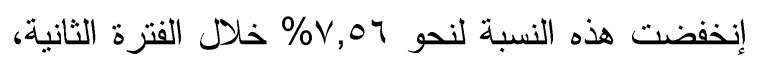
بمعدل إنخفاض قدر بنحو V, •r\%، وتبين أن نصيب

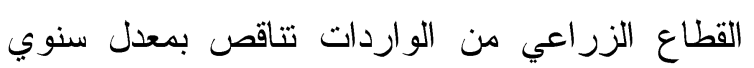

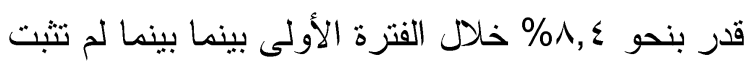

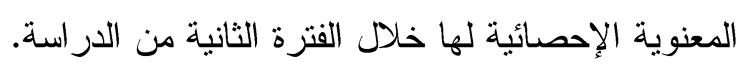

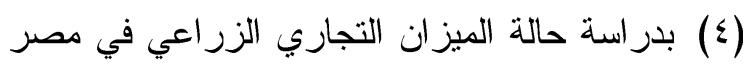

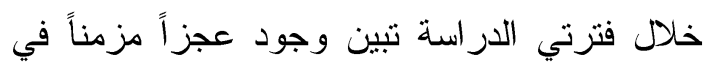
جميع سنوات الدراسة، حيث تفوقت قيمة الواردات على قيمة الصادر ات ومنها تبين أن نسبة الصادرات

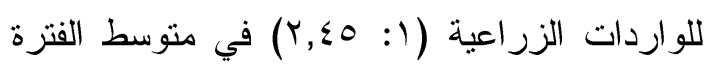

(1) بدراسة حجم التجارة الخارجية الزراعية خلال

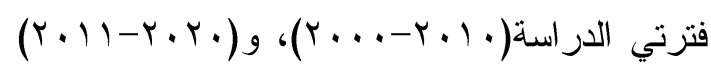

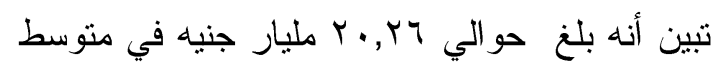

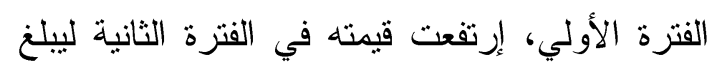
حوالي NV,Vo مليار جنيه، أب أن حجم التجارة

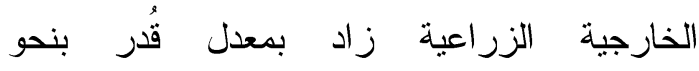

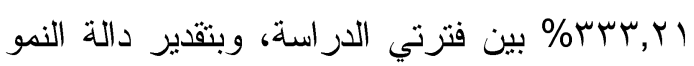

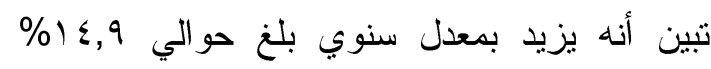

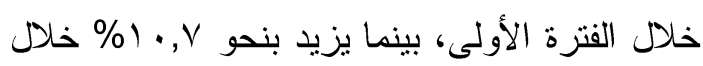
الفترة الثانية. وتجدر الإشارة إلى أن القطاع الزراعي ساهم بنحو

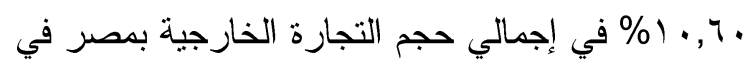

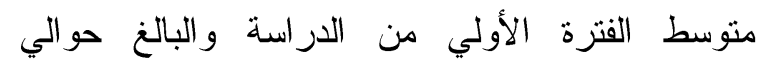

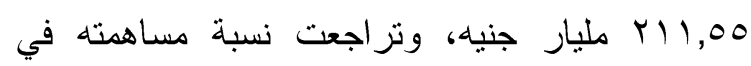

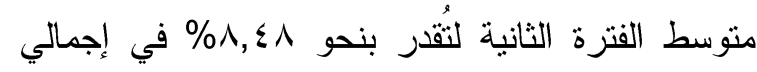

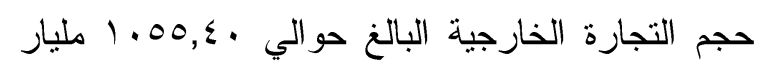

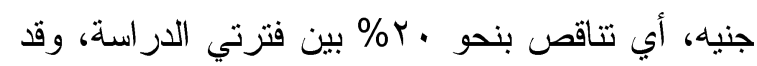

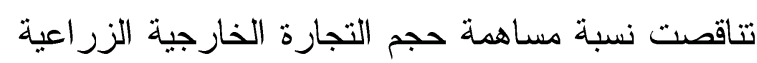
في إجمالي حجم التجارة الخارجية بمصر تنين أنه

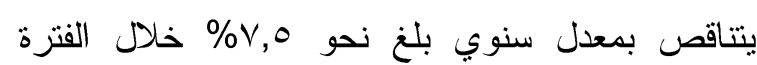

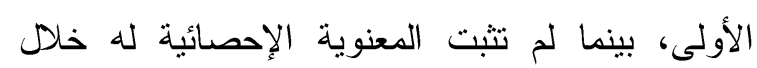

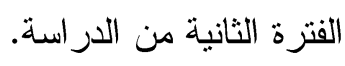

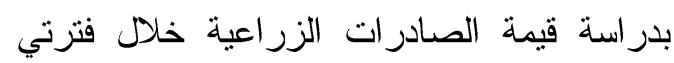

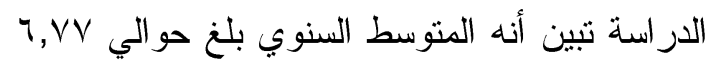
مليار جنيه خلال الفترة الأولى، بينما بلغ حوالي لئي

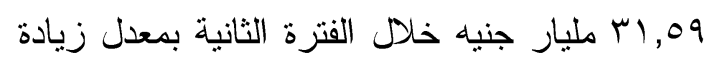

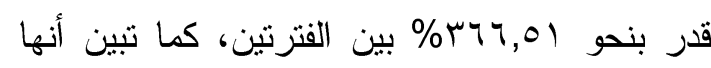

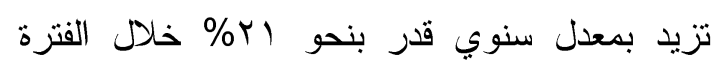

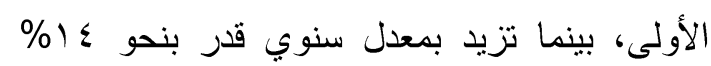

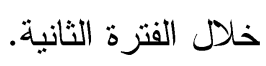
كما تنين أن الصادرات الزراعية تساهم بنحو

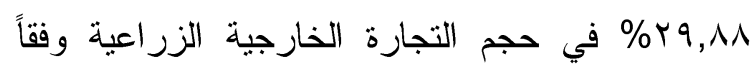

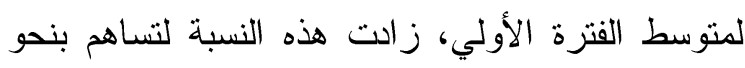

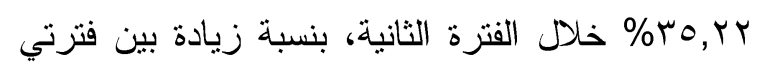


وبتقدير التغير النسبي للصادرات الزراعية خلال سنوات الفترة الثانية من الدراسة تبين أن أقصى زيادة

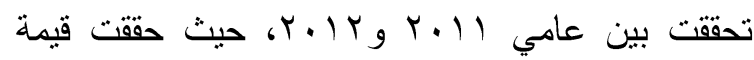

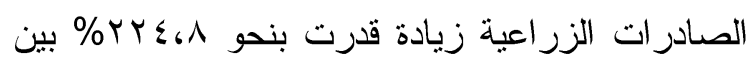

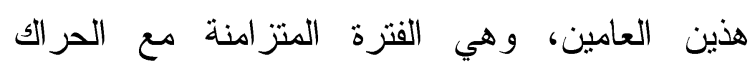

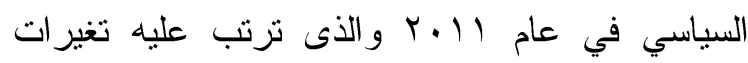

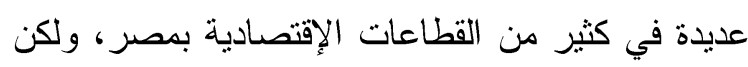

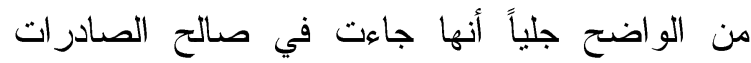

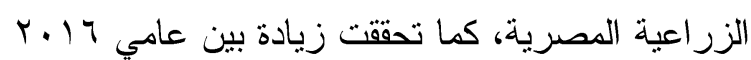

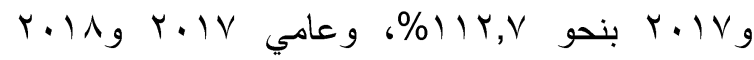

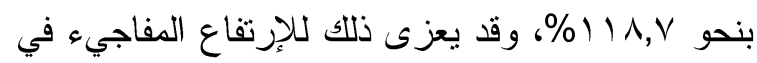

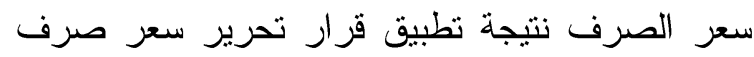

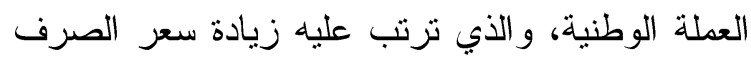

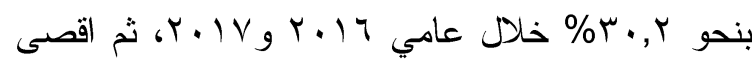

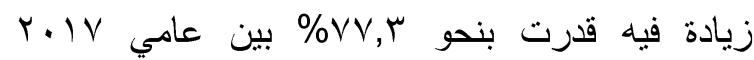

$$
\text { .r. 11 g }
$$

كما تبين أيضاً أن قيمة الصادرات الزراعية

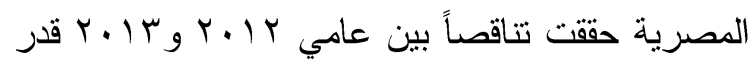

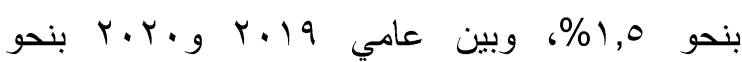

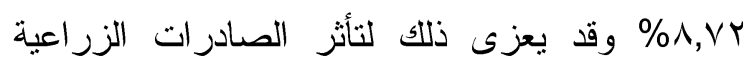
بالعديد من العو امل منها إنخفاض سعر الصرف درف بنحو

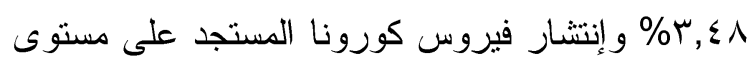

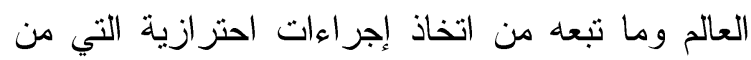

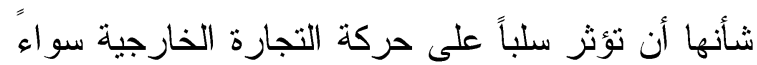

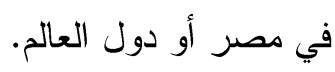
(ب) بدراسة التغير النسبي في قيمة الواردات الزر اعية

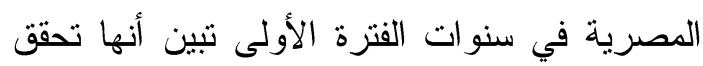
زيادة في معظم سنوات هذه الفترة، كما تبين أن

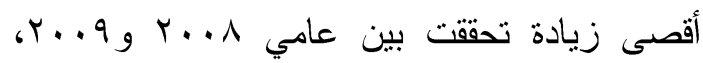

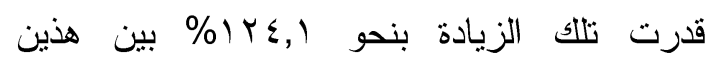

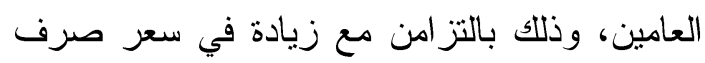

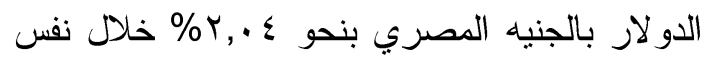
العامين، كما تبين أن أقصى إنخفاض في هذه القيمة

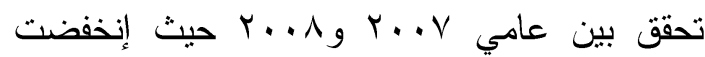

الأولى من الدراسة، بينما قدرت بنحو (1: 19,1, ) في متوسط الفترة الثانية، كما تبين أن قيمة العجز لأنس في الميزان التجاري الزراعي في مصر بلغت

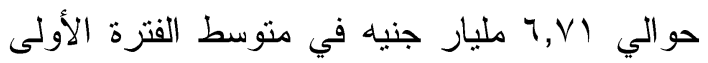

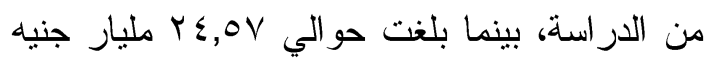

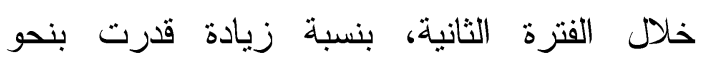

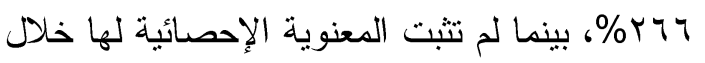
فترتي الدراسة. ومن الجدير بالذكر أن قيمة العجز في التجارة

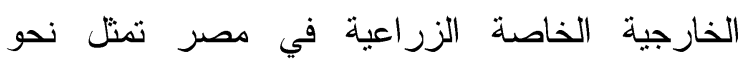

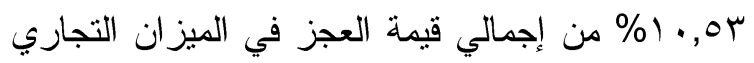

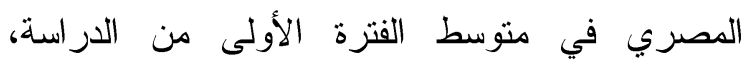

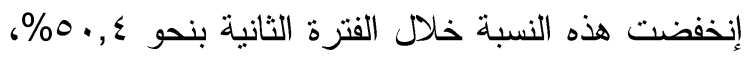
حيث بلغ نصيب القطاع الزراعي من قيمة هذا العجز خلال هذه الفترة نحو سr, \%\%، وقد تبين أن نصيب القطاع الزراعي من العجز في الميزان التجاري في ولهي فترتي الدراسة تناقص بمعدل سنوي غير معنوي

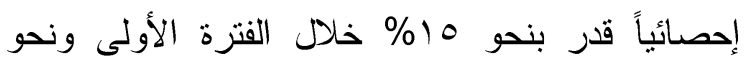
\%, خ خلال الفترة الثانية من الدراسة. (0) بدراسة التغير النسبي في التجارة الخارجية الزراعية خلال سنوات الدراسة تبين ما يلي:

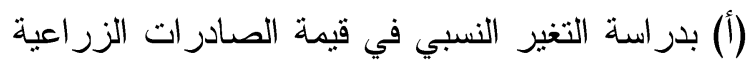

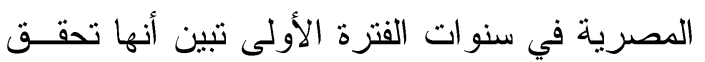

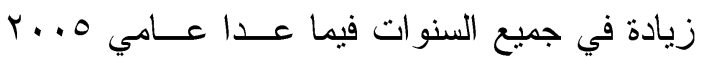

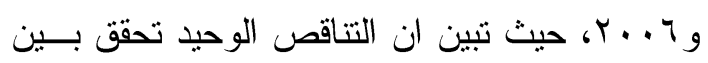

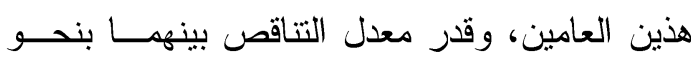

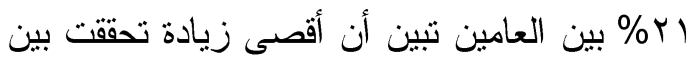

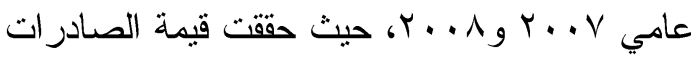

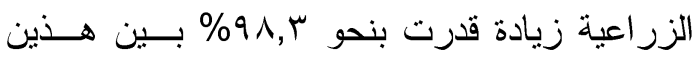

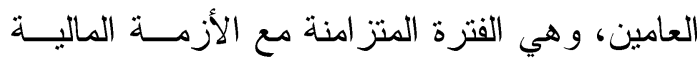
العالمية و إنخفاض في سعر صرف الدولار بالجنيه

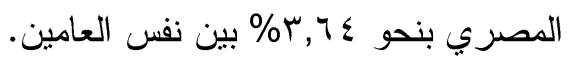


الواردات بنحو \%rr,0\%، الأمر الذي أدى لأقصى

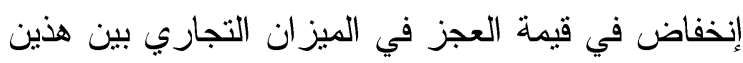

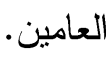

ومما سبق يتضح أن الإنخفاض في قيمة العجز

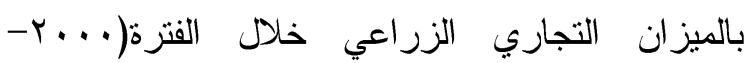

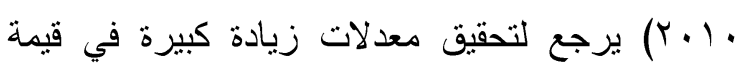

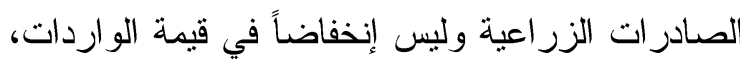

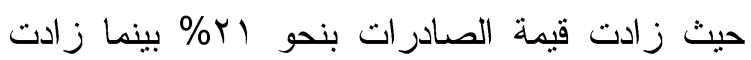

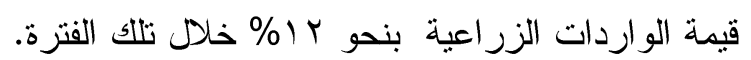

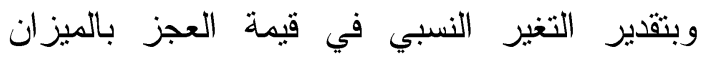
التجاري الزراعي خلال سنوات الفنزة الثانية تبين أن الن بانير

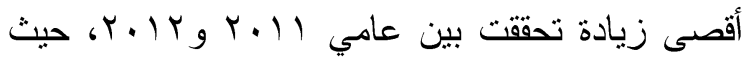

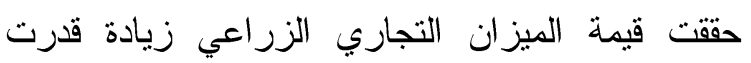

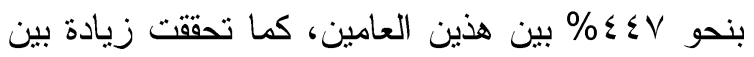

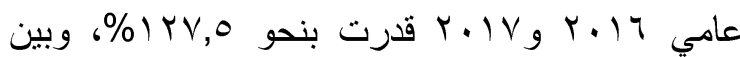

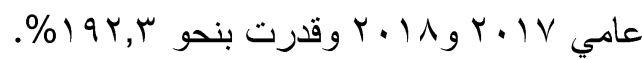

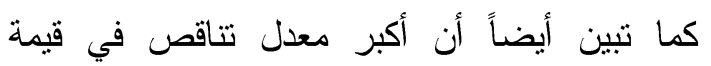
الميزان التجاري الزراعي خلال هذه الفترة تحقق بين

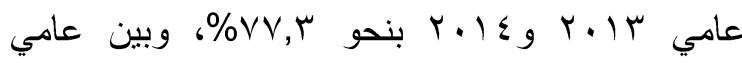

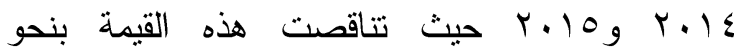
عro,1\%، أما عن أثر انتشار فيروس كورونا المستجد

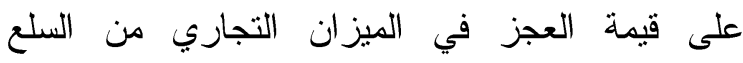

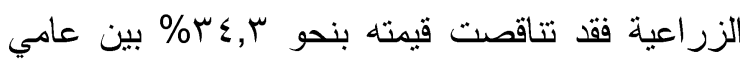

$$
\text { r.r. G. T. } 19
$$

من الإستعراض السابق للبيانات بمكن القول بأن القطاع الزراعي ساهم في تخفيف العبء الإقتصادي على المتصدد المصري خلال العقد الثاني من القرن الحالي من حيث مساهمته في التجارة الخارجية الزراعية فقد تحققت زيادة في مساهمة القطاع الزراعي في الصادرات خلال العقد الثاني بنحو ؟,، (1\%، وكذلك فقد نراجع العبء الذي قد يمثله القطاع الزراعي على بلى الته الميزان التجاري، حيث تبين إنخفاض معدل النمو في التي

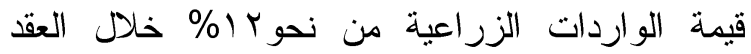
الأول إلى نحو 9\% خلال العقد الثاني.

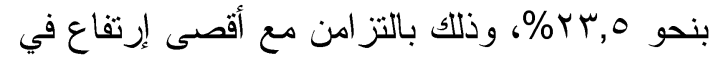

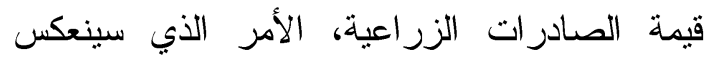

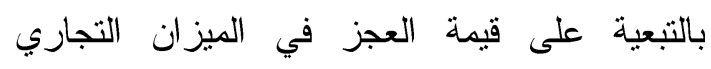
الزر اعي خلال هذه الفترة.

وبتقدير التغير النسبي للواردات الزراعية خلال الفنرة الثانية من الدراسة تبين أن أقصى زيادة تحققت

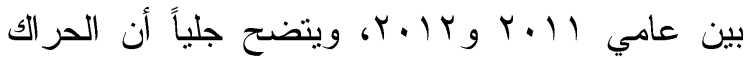

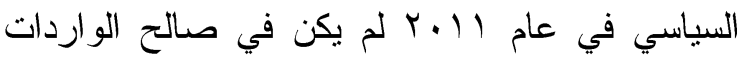
الزراعية المصرية، حيث حققت قيمة الواردات

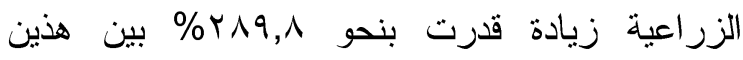

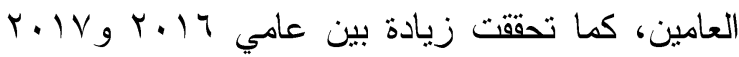

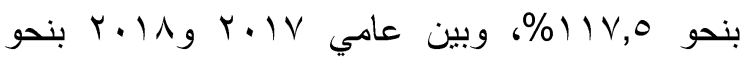
$\% 1 \leqslant \varepsilon, 9$

كما تبين أيضاً أن أقصى تناقص في قيمة الواردات

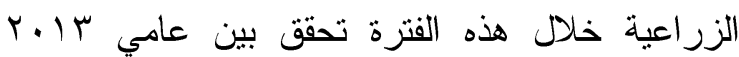

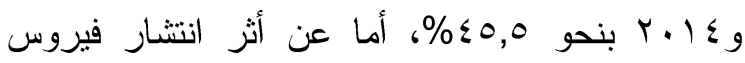

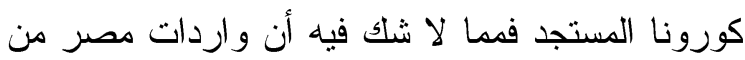

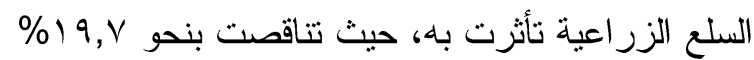

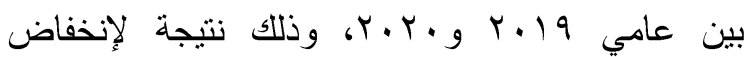
حركة التجارة الخارجية على مستوى العالم. (ج) بدراسة التغير النسبي في قيمة العجز بالميزان التجاري الزراعي في مصر خلال سنوات الفنرة الأولى تبين تحقق زيادة في معظم سنوات هذه

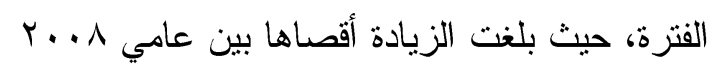

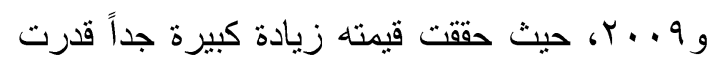

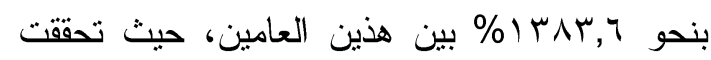
خلال نلك السنة أقصى زيادة في قيمة الواردات

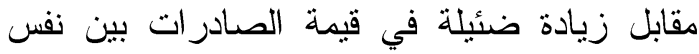

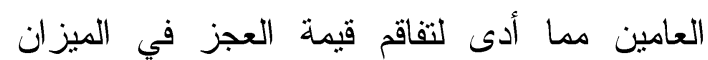

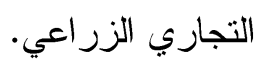

كما تبين أن أقصى إنخفاض في هذه القيمة تحقق

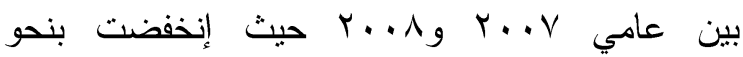
r.,19\%، حيث حققت قيمة الصادرات الزراعية

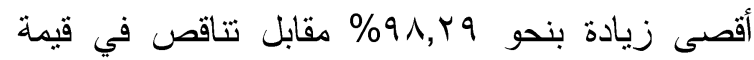


وأسفرت نتائج التحليل عن عدم وجود تأثير معنوي

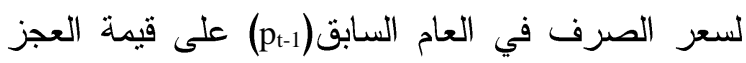
في الميزان التجاري الزراعي، وتوضح نتائج التحليل الواردة بالجدول (r) أنه لم يتم قبول نموذجي الإنحدار

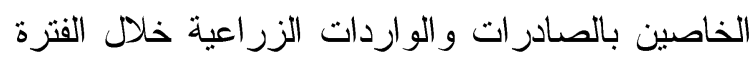
الأولى نظر اً لعدم صلاحية النموذج من الناحية القياسية.

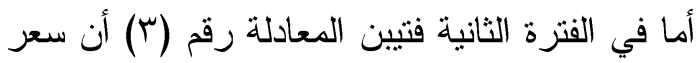

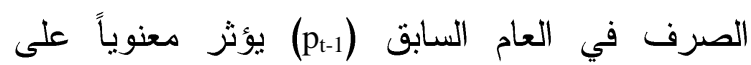

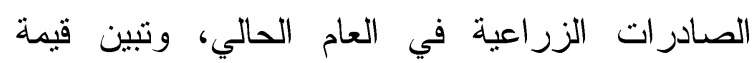

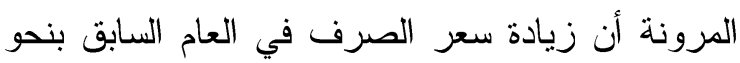

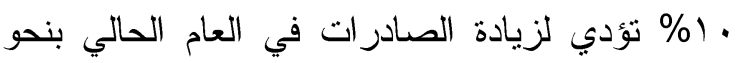
\% \%,V

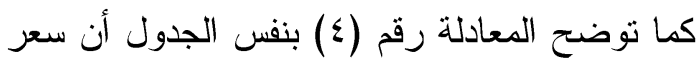
الصرف في العام السابق يؤثر معنوياً على الواردات الزراعية في العام الحالي، وتبين قيمة المرونة أن زيادة

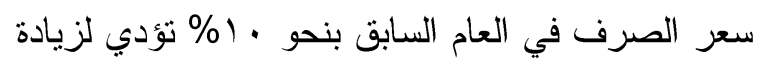

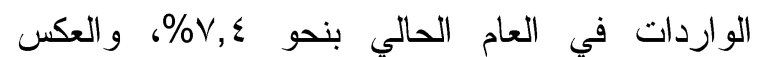

صحيح.

وبصورةٍ عامة ومن خلال ما تم التوصل إليه من التحليل السابق يتبين أن زيادة سعر الصرف وند في في في

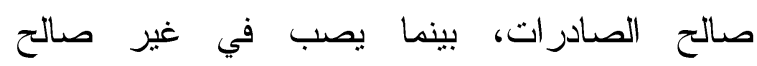
الواردات، وذلك خلال العقد الثاني من القرن الواحد
كما تبين تزاجع هذا العبء بصورة أكبر من خلال

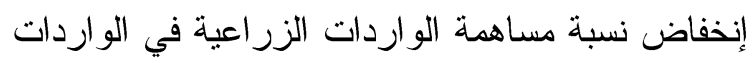

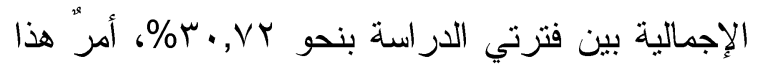

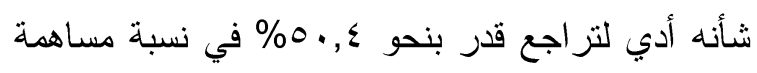

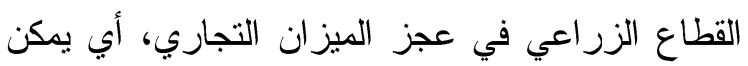

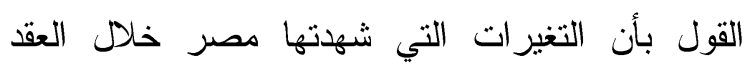

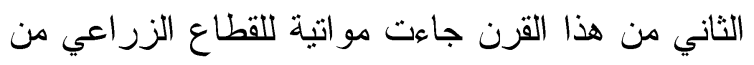

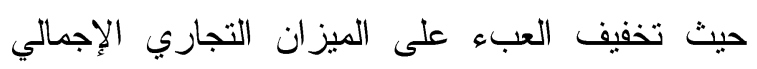
حتى في ظل تراجع قيمة صادرته خلال العقد الثاني عما كانت عليه في العقد الأول. (T) بدراسة أثر التغير في سعر صرف الجنيه المصري

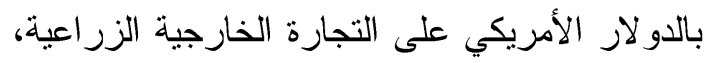

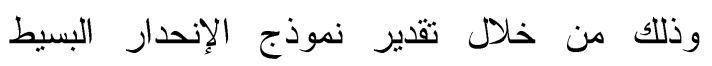

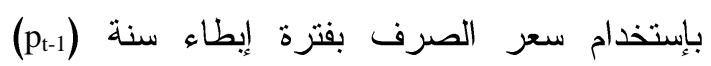
كمتغير تفسيري، وحيث تبين وجود فروق معنوية

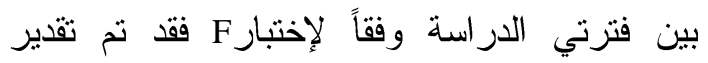
نموذج الإنحدار البسيط لكل فترة على حدة، وذلك لكئل

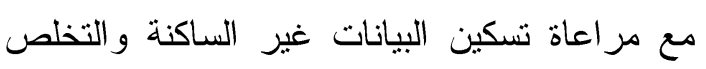
من المشاكل القياسية في سلسلة البيانات، ثم نم تقدير

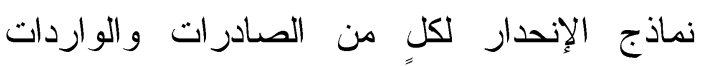
الزراعبة كل على حدة، وكذلك لقيمة العجز في ولادي الميزان التجاري الزر اعي خلال فترتي الدر اسة. و العشرين.

جدول r: نماذج الإحدار البسيط المقدرة بين سعر الصرف فى مصر كمتغير مستقل وكل من الصادرات والواردات

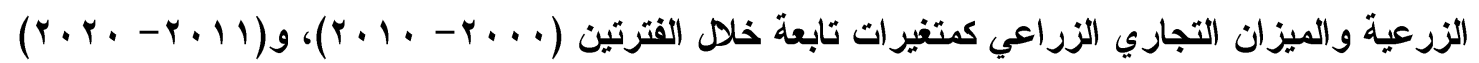

\begin{tabular}{|c|c|c|c|c|}
\hline $\mathbf{F}$ & $\mathbf{R}^{2}$ & المعادلة & المتغير التابع & 'จ \\
\hline$(10.254)^{*}$ & 0.56 & $\begin{array}{c}\operatorname{lnEXP} \mathrm{P}_{1 \mathrm{t}}=\ln .10+2.53 \mathrm{InP}_{\mathrm{t}-1} \\
(0.782)^{\mathrm{n} . \mathrm{s}}(53.202)^{*}\end{array}$ & قيمة الصنادر ات الزر اعية في الفترة الأولى & 1 \\
\hline$(86.29)^{* *}$ & 0.92 & $\begin{array}{r}\operatorname{lnEXP} P_{2 \mathrm{t}}=\ln 3.35+0.97 \mathrm{InP}_{\mathrm{t}-1} \\
(4.254)^{* * *}(9.289)^{* * *}\end{array}$ & قليمة الصنادرات الزر اعية في الفترة الثانية & r \\
\hline$(6.315)^{*}$ & 0.44 & $\begin{aligned} \text { LnIMP }_{1 \mathrm{t}} & =\ln 1.341+1.41 \mathrm{InP}_{\mathrm{t}-1} \\
(1.100)^{\mathrm{n} . \mathrm{s}} & (2.645)^{*}\end{aligned}$ & قليمة الواردات الزر اعية في الفترة الأولى & $r$ \\
\hline$(15729)^{* *}$ & 0.66 & $\begin{aligned} \operatorname{lnIMP} & =\ln 10.17+0.74 \mathrm{InP}_{\mathrm{t}-1} \\
(2.380)^{*} & (3.966)^{* *}\end{aligned}$ & قيمة الو اردات الزر اعية في الفترة الثانية & $\varepsilon$ \\
\hline
\end{tabular}
المصدر - نتائج التحليل الإحصائى للبيانات الو اردة بالجدولين (1) و و(؟) بالبحث، و الجدول ( (1) بالملحق. 


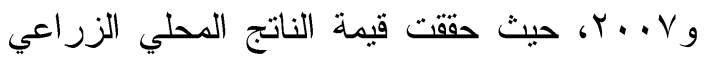

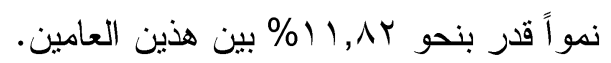

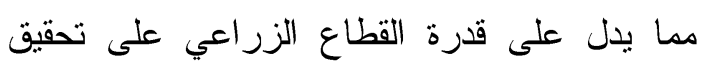
نمواً في النشاط الإقتصادي في معظم سنوات الفترة الأولى من الدراسة، ولكنه عانى من إنكماش في حجم

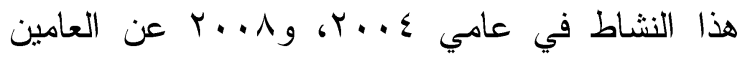
السابقين لهما، علماً بأن هذين العامين تزامن فيهما هذا عأها الإنكماش مع تعويم الجنيه المصري خلال عامين

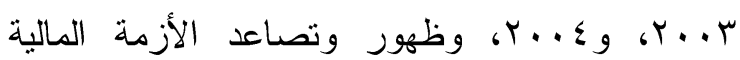
العالمية التي تركت أثار ها على العديد من أوجه النشاط الإقتصادي في عام م . . r. وبتقدير التغير النسبي للناتج المحلي الزراعي خلال

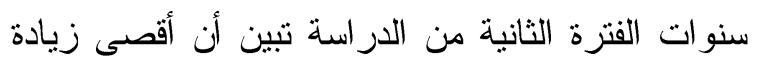

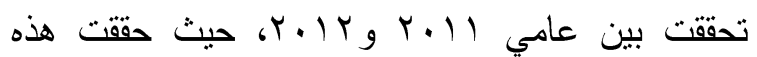

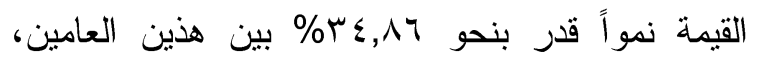
وهي كما سبق الذكر فترة متز امنة مع الحر الك السياسي

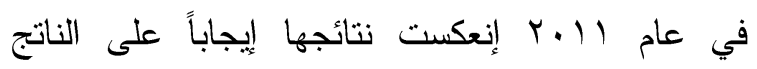
المحلي الزراعي أثناء محاولات للسيطرة على بعض فئل

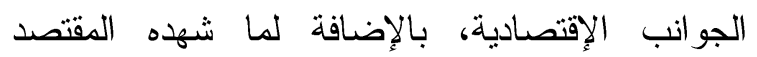

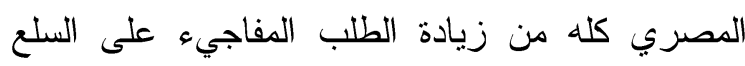

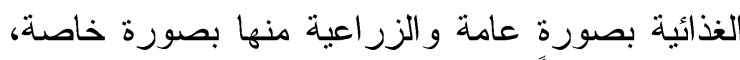

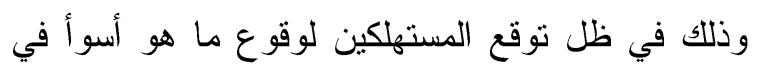

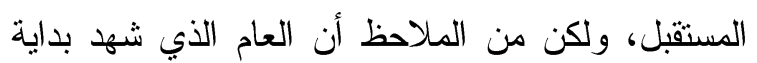

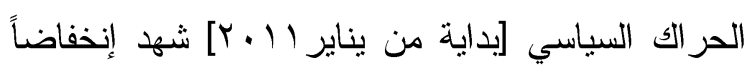

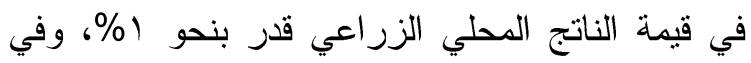

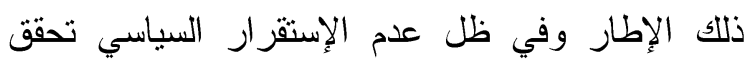

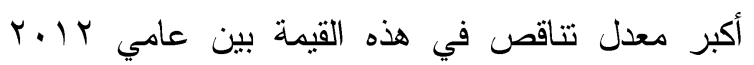

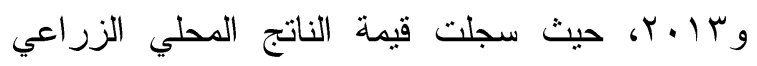

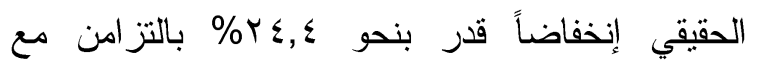
تصاعد التغير ات السياسية.
ثانياً: تقييم أداء القطاع الزراعي من حيث مســاهته في الناتج المحلي الإجمالي إهتم البحث في هذا الجزء بدراسة وتقدير القيمة

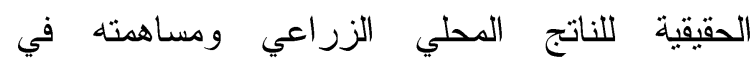
الإجمالي، وتقدير معدل التغير النسبي للناتج المحلي الزراعي وذللك لقياس مدى النمو أو الإنكماش في النشاط الإقتصادي بهذا القطاع، حيث بدراسة البيانات الواردة بالجدول (ع) تم التوصل للنتائج التالية:

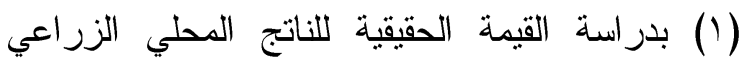
خلال فترتي الدراسة تبين أن متوسطها خلال الفترة

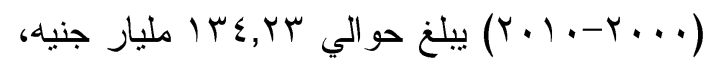

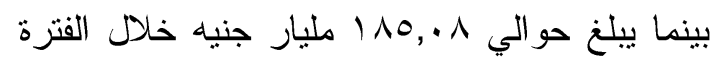

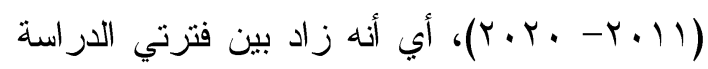

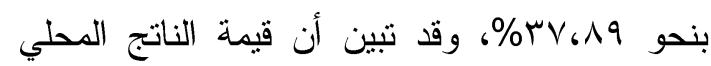

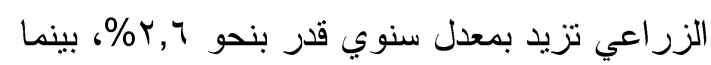

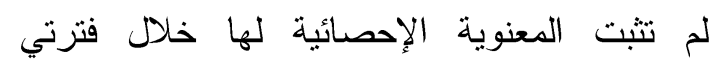

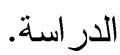
ومن جهةٍ أخرى نوضح البيانات أن قيمة الناتج

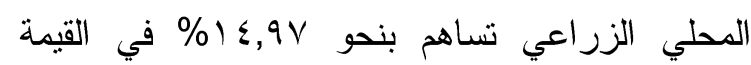
الحقيقية للناتج المحلي الإجمالي في منتوسط الفترة الأولي، إنخفضت هذه النسبة لتساهم بنحو

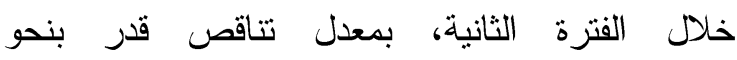

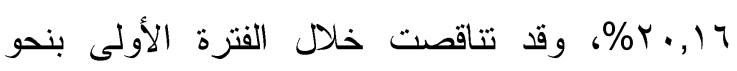

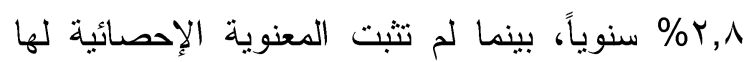

$$
\text { خلال فترتي الدر اسة. }
$$

(Y) بتقدير التغير النسبي للناتج المحلي الزراعي خله

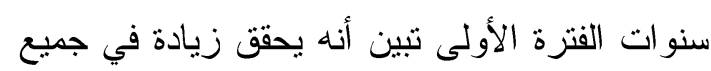

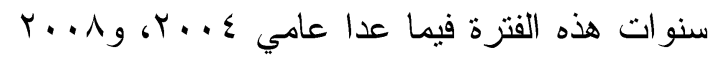
عن الأعوام السابقة لهما، بينما حققت هذه القيمة عادئ

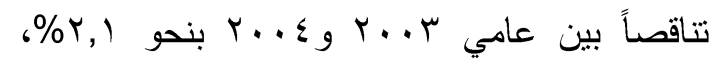

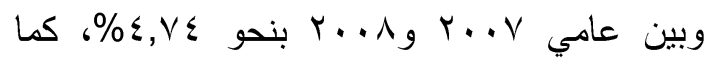

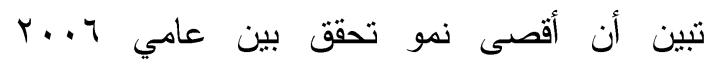


جدول ع: تطور القيمة الحقيقية للناتج المحلي الزراعي ومساهته في الناتج المحلي الإجمالي فــي مصـر خــلا

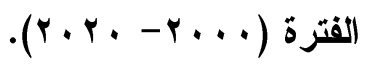

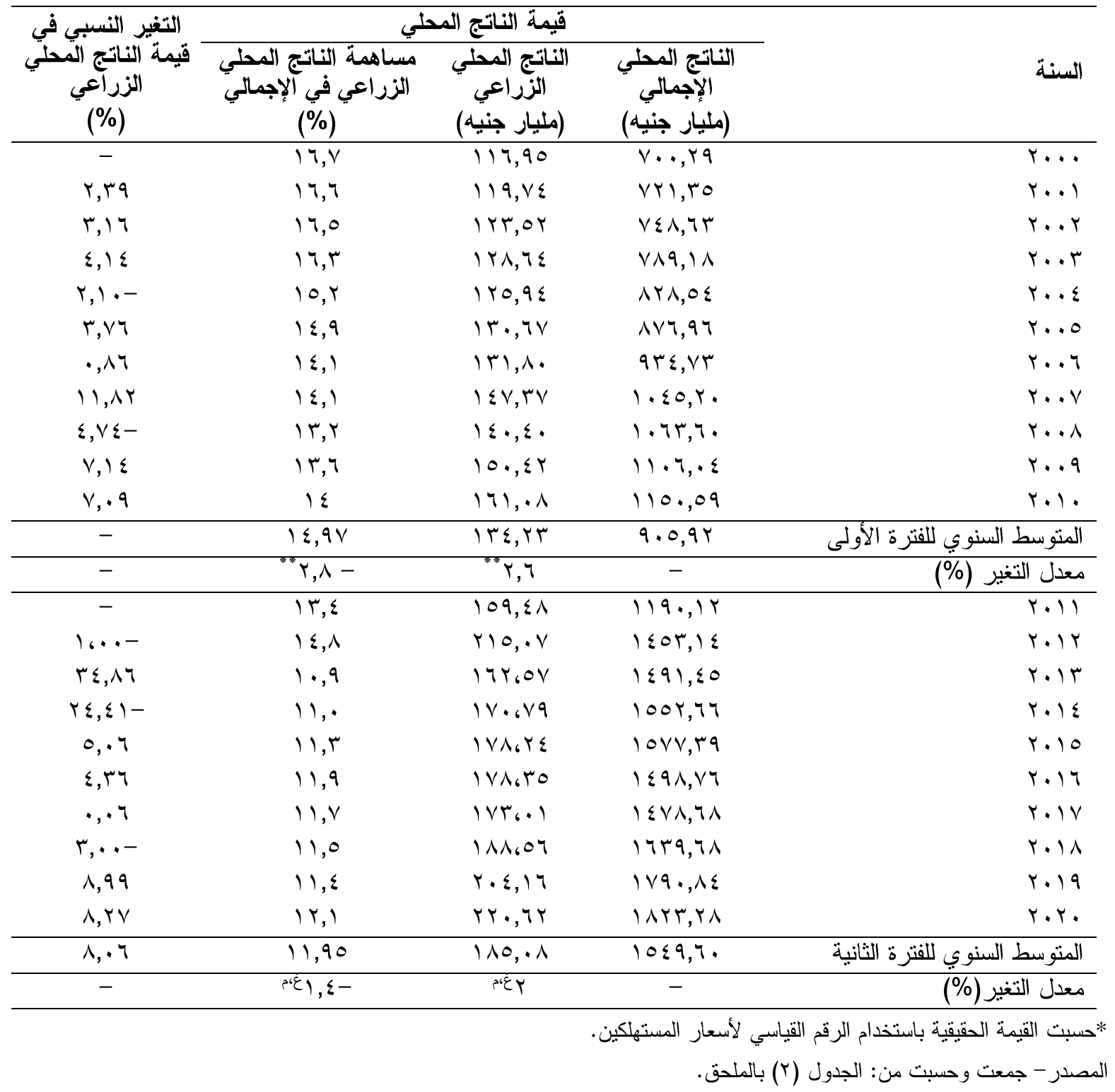

كما يلاحظ أن القطاع الزراعي حقق إنكماثاً في حيث مساهته في الناتج المحلي الإجمالي، وذللك بين

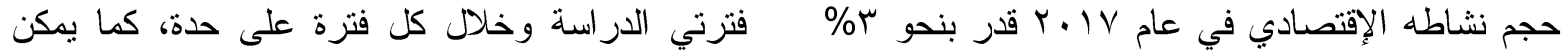

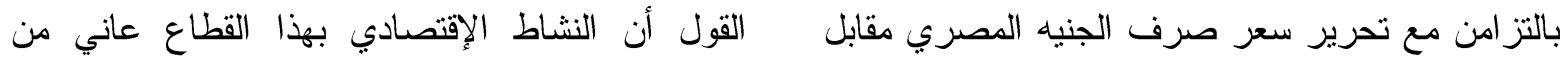

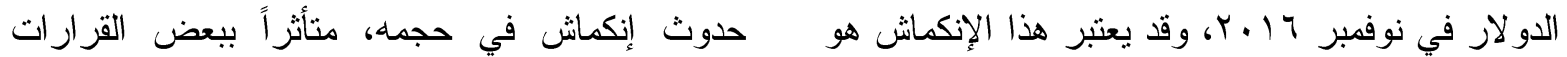
أحد الآثار السلبية لهذا الإجر اء الإقتصادي، ولكن تم الإقتصادية التي تم إتخاذها بالمقتصد المصري، وكذلك

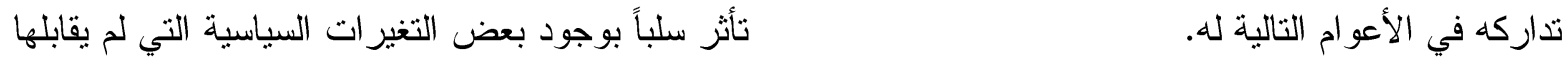
من خلال ما سبق بيانه بمكن القول بأن القطاع تغيرات إقتصادية، بالإضافة لتأثره سلباً بالأحداث الزراعي نراجع في أداء دوره في المقتصد القومي من فن لان لان 
الإقتصادية العالمية، وقد اتضح ذلك جلياً في تزاجع الزراعي الأفقي، حيث تبين البيانات الواردة بالجدول (0) القيمة الحقيقة للناتج المحلي الزر اعي.

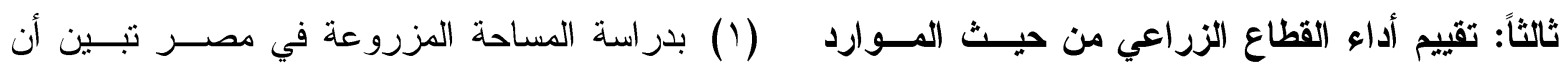

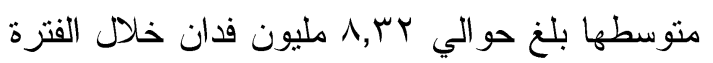

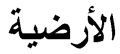

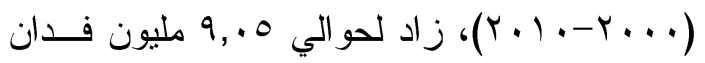
فيما يلي توصيفاً للموارد الأرضية المستغلة في الارصيه

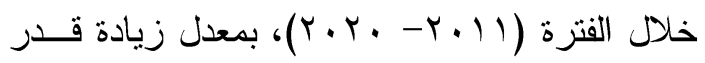

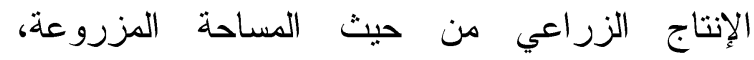

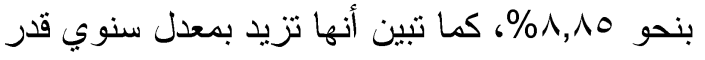

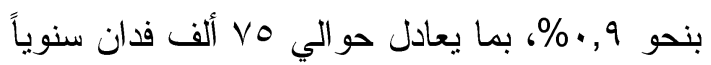

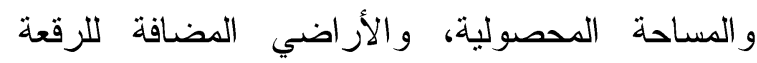
الزراعية من خلال الإستصداح، ورصد التغيرات التي ولاتي

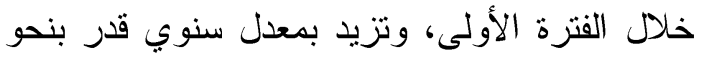

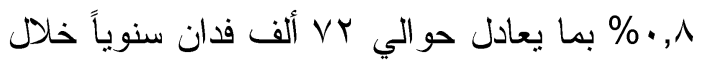
حدثت في تلك الموارد خلال فترة الدراسة، مع إلقاء الضوء على أهم المشروعات القومية المستهدفة للتوسع

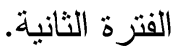

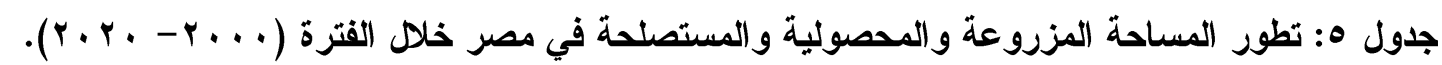

\begin{tabular}{|c|c|c|c|c|c|}
\hline المستصلحية الأرسة & الزيكثيف & المحصولية(ب) & السنوي للمسناحة التغيرة & المزروعة (1) & السنة \\
\hline (ألف فدان) & $(1) /(r)$ & مليون فدان & (ألف فذان) & مليون فدان & \\
\hline rr & $1, \vee \wedge$ & $1 \varepsilon$ & - & $V, \wedge \Gamma$ & r... \\
\hline Ir,V & $1, V V$ & $1 \leqslant$ & M & $\vee, 90$ & $r \ldots 1$ \\
\hline$r \wedge, V$ & $1,1 / 4$ & $1 \leqslant$ & $r \cdot Y, V T$ & 1,10 & $r \ldots r$ \\
\hline 11 & $1, \vee \wedge$ & $1 \varepsilon$ & $r_{0, \cdot \lambda-}$ & $\Lambda, 11$ & $r \ldots r$ \\
\hline rT,O & $1,1 / 4$ & 10 & $170, \varepsilon r$ & $\Lambda, Y \wedge$ & $r \ldots \varepsilon$ \\
\hline $1 \leqslant, 0$ & $1, v \wedge$ & 10 & $1 \cdot 7, r_{0}$ & $\Lambda, r q$ & r... \\
\hline$\Gamma_{\Lambda}, \lambda$ & $1, V V$ & $1 \leqslant, 9$ & $r q, \ldots$ & $\wedge, \varepsilon)$ & $r \ldots r$ \\
\hline T & $1, \Lambda$. & $10,1 \mathrm{~V}$ & $1, \ldots$ & $\wedge, \varepsilon Y$ & $r \ldots v$ \\
\hline $90, r$ & $1, \lambda 1$ & 10 & $9, \ldots$ & $\Lambda, \varepsilon \Gamma$ & $r \ldots \Lambda$ \\
\hline ץ & 1,194 & 17 & $r_{01, \ldots}$ & $\wedge, \vee \wedge$ & $r \ldots q$ \\
\hline $1 \leqslant, V$ & 1, vo & 10 & $\leqslant r, \ldots-$ & $\Lambda, \vee \leqslant$ & $r .1$. \\
\hline$\varepsilon \wedge, \vee \leqslant$ & $1, V V$ & 10 & - & $\Lambda, r Y$ & المتوسط السنوي للفترة الأولى \\
\hline 19 & & *i,r & - & $\cdot, 9$ & معدل التغير (\%) \\
\hline 10,0 & $1, v \wedge$ & 10,10 & TrY, ..- & 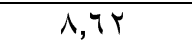 & $r .11$ \\
\hline rq & $1, \mathrm{VV}$ & $10,0 \mathrm{~V}$ & $1 \wedge \cdot, \ldots$ & $\wedge, \wedge$. & $r .1 r$ \\
\hline$r Y, q$ & $1, V r$ & $10, \leqslant 9$ & $100, \ldots$ & 1,90 & $r . \mid r$ \\
\hline YY,T & 1,174 & 10,79 & ґ৯,..- & $\Lambda, 9 r$ & $r \cdot 1 \varepsilon$ \\
\hline $1 \leq, 0$ & I,VY & $10,7 \varepsilon$ & $1 \wedge \cdot, \ldots$ & 9,1 . & $r .10$ \\
\hline$\Gamma \Lambda, 0$ & $1, v \varepsilon$ & 10,1 & $0, \ldots$ & 9,1 . & $r .17$ \\
\hline$r \wedge, 9$ & 1,147 & $17, .0$ & ו,... & 9,14 & $r . I V$ \\
\hline $09, r$ & $1, v_{0}$ & $17, \cdot 7$ & $09, \ldots$ & 9,19 & $r \cdot 1 \wedge$ \\
\hline $110, \mathrm{~V}$ & $1, v \leqslant$ & $17, Y r$ & $1 \leqslant r, \ldots$ & q, ( & $r .19$ \\
\hline$v$. & $1, v \varepsilon$ & $17, \mathrm{r}$ & $T V, \ldots$ & $9, \varepsilon$ & $r \cdot r$. \\
\hline$\{r, 7 \wedge$ & $1, v \varepsilon$ & $10, \mathrm{VV}$ & - & $9, .0$ & المتوسط السنوي للفترة الثانية \\
\hline$*, 1 \vee$ & - & $\cdot, \mathrm{V}$ & - & $\cdot, \wedge$ & معدل التغير السنوي (\%) \\
\hline
\end{tabular}

المصدر - جمعت وحسبت من: بيانات منشورة بالموقع الإكتروني لوزارة التخطيط و التتمية الإقتصادية: (mped.gov.eg) 
خلال الفترة الأولى بنحو VV VV I,V

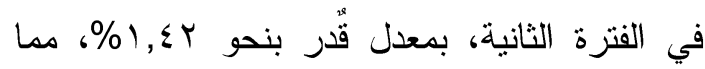

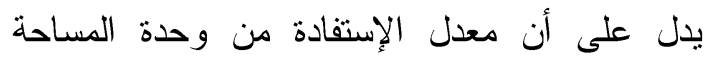

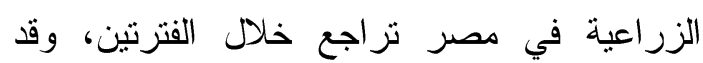
يرجع ذلك لعدة عوامل منها التعدي على الأراضي في فئري

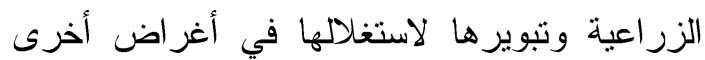
بخلاف الإنتاج النباتي، وعدم العناية الكافية بالتوسع التونية الزر اعي الر أسي خلال الفترة الثانية.

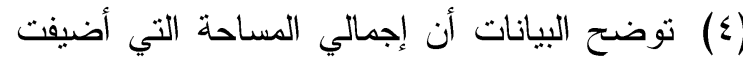

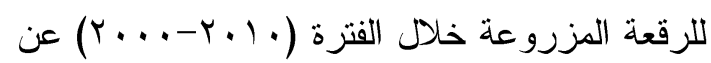
طريق الإستصلاح قدرت بحوالي ا, بسه ألف فدان

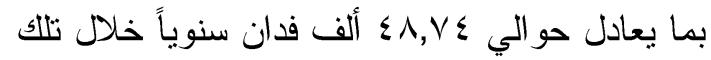
الفترة، في حين قدرت تلك المساحة خلال الفترة

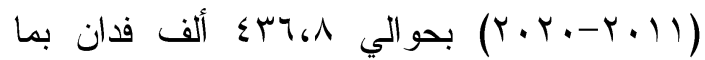

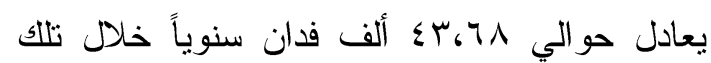
الفتزة، وبصورة عامة فإن إجمالي المساحة المستصلحة خلال الفترة الكلية للاراسة [ابنة سنة]

$$
\text { قدرت بحو الي و qVY, } 9 \text { ألف فدان. }
$$

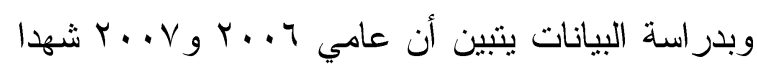

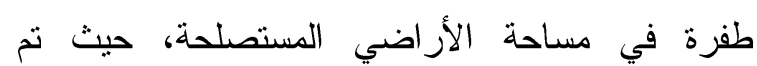
استصدلاح أكبر مساحة خلال الفترة الأولى من الدراسة،

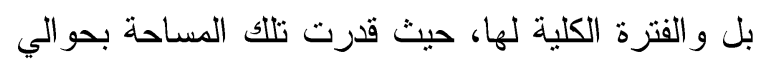

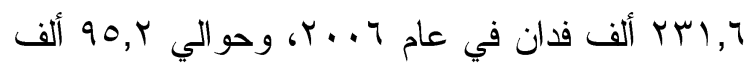

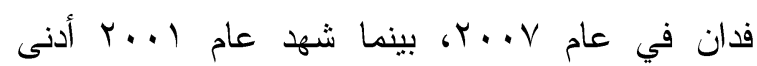

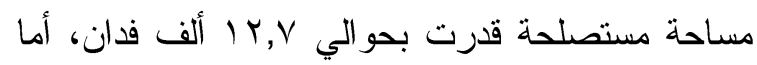

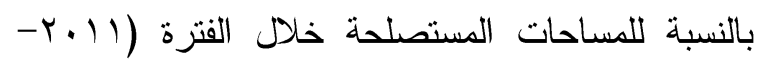

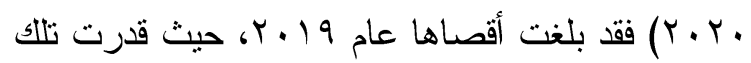

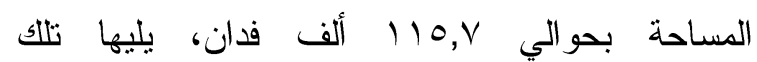

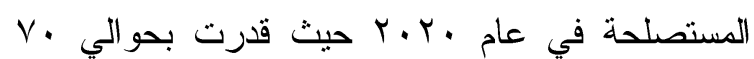
ألف فدان. وجدير" بالذكر أنه تم البدء في عدة مشروعات قومية

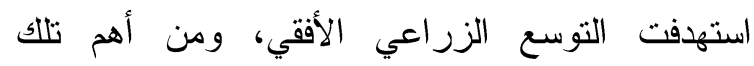

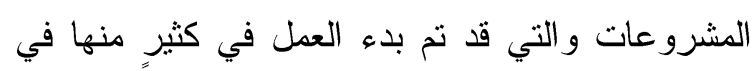

وبتقدير مقدار التغير في إجمالي المساحة المزروعة و الذي يمثل التغيرات التي تحدث سواءً بالإضافة نتيجة

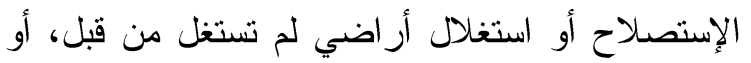

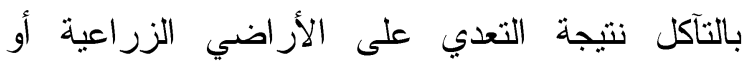
تبويز ها لأي سبب وذلك خلال فترتي الدراسة، ومنه

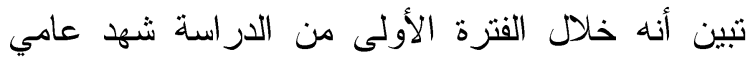

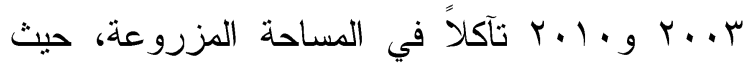

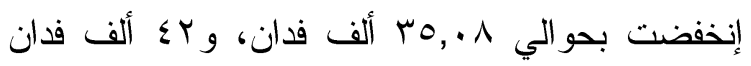

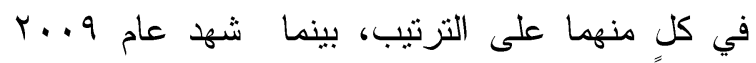
أكبر مساحة مضافةً لإجمالي الرقعة الزر اعية، حيث ليثل

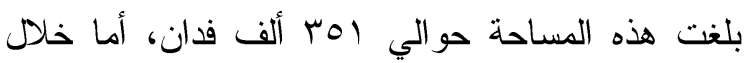

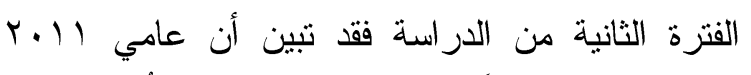

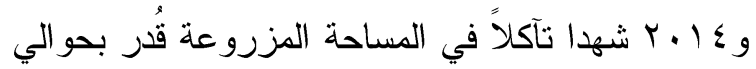

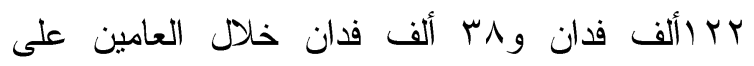

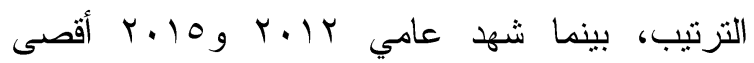

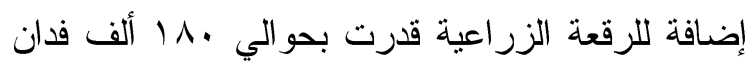

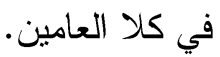
(Y) بدراسة الموارد الأرضية المستغلة في الإنتاج

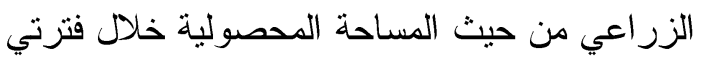

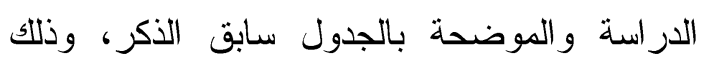

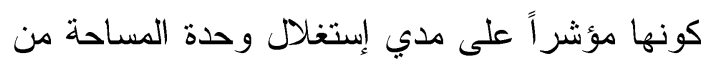

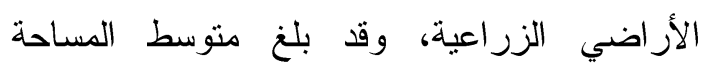

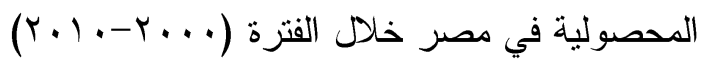

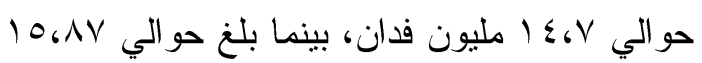

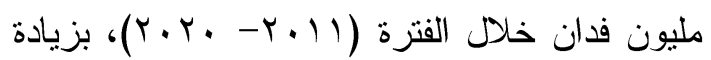

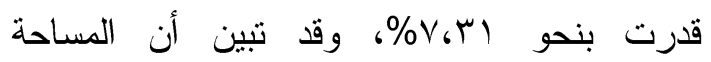

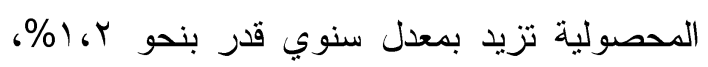
بما يعادل حو الي VI ألف فدان سنوياً خلال الفترة الأولى، بينما تزيد بمعدل سنوي قدر بنحو V، •. بما يعادل حوالي • 11 ألف فدان سنوياً خلال الفترة

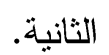
(r)من خلال المساحة المزروعة والمساحة المحصولية تم إستتناج معدل التكثيف الزر اعي وقد قدر متوسطه ولهد 


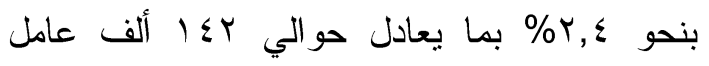
سنوياً خلال الفترة الثانية.

توضح البيانات أن القطاع الزراعي يستوعب ماله

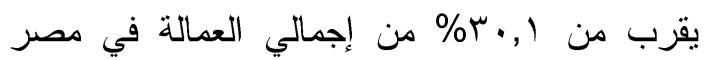

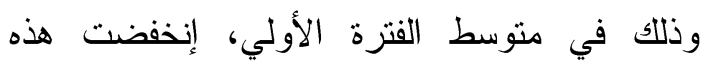

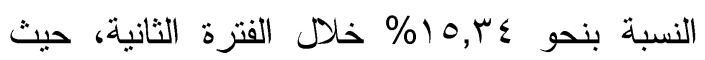
توضح البيانات أن القطاع الزراعي تراجع عن دوره في إستيعاب مزيداً من العمالة باستيعابه نحو الزّاع

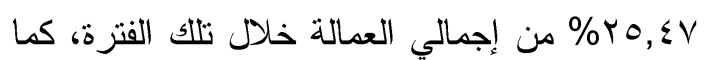
تبين أن هذه النسبة تزيد سنوياً بنحو 0 , \% خلادل

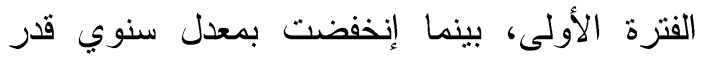

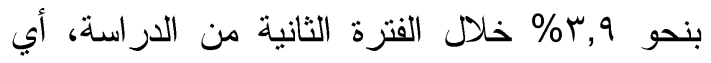
يمكن القول أن هذا القطاع تحول من قطاعاً مستو عباً للعمالة لقطاع طارداً لها. (r) بتقدير التغير النسبي للعمالة الزراعية خلال الفترة الأولى تبين أن هذه الفترة شهدت إنتعانشاً ملحوظاً في سوق العمل بالقطاع الزراعي، حيث تحققت

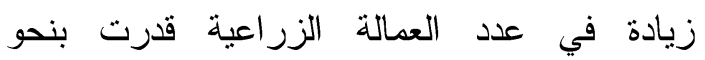

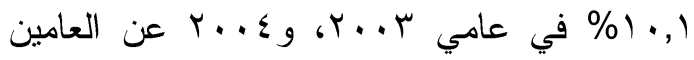

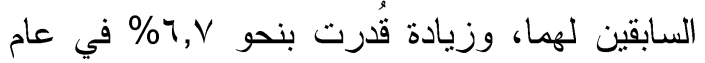

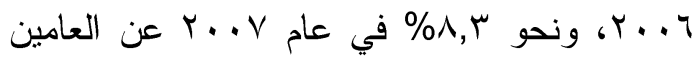
السابقين لهما على الترتيب، وجدير" بالذكر أن هذه

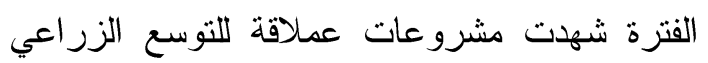
الأفقي الأمر الذي انعكست آثاره على إستيعاب المزيد من العمالة الزر اعية.

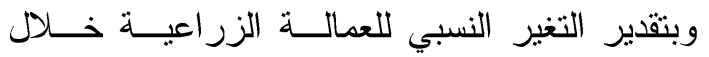

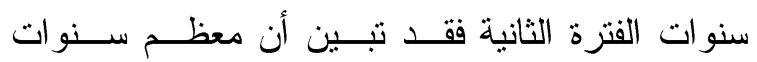

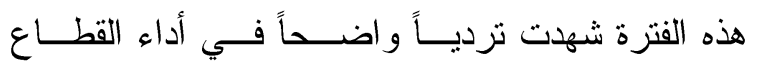
الزر اعي من حيث إستيعاب العمالــة، خاصـــة عـــامي

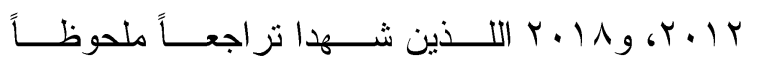

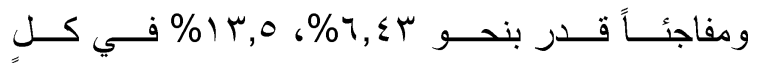
منهما على الترتيب عن العامين السابقين لهما.
النصف الثاني من تسعينيات القرن العشرين هي:

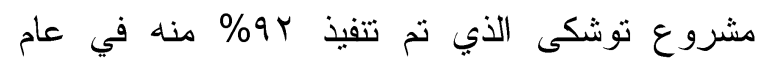

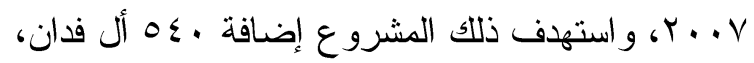

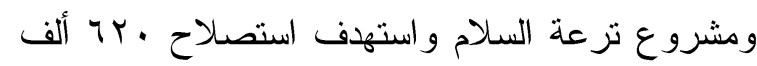
فدان شرق وغرب قناة السويس، ومشروع شرق وق ونه

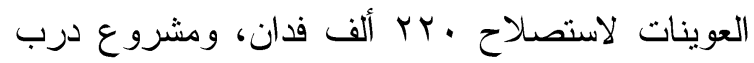
الأربعين لاستصلاح r ألف فدان، ومشروع إنشاء

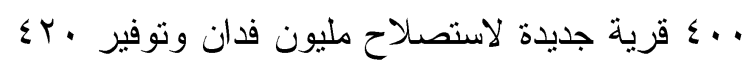

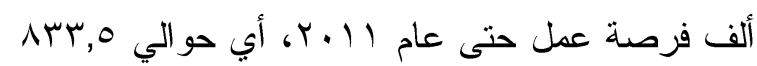

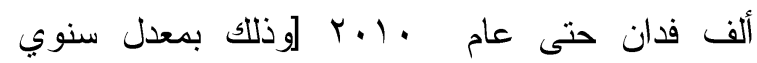
177,V المشروعات مردوداً إقتصادياً وإجتماعياً قد يتم تناول لألهاك

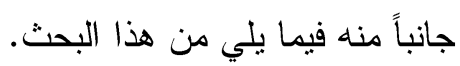
رابعاً: تقييم أداء القطاع الزراعي من حيث هيث قدرته على تشغيل و إستيعاب العمالة يتتاول هذا الجزء من البحث ثقيبماً لددى قدرة

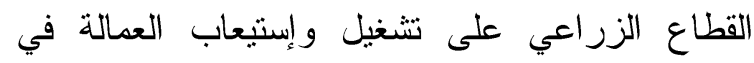
مصر، مع الأخذ في الإعتبار أثز المشروعات القومية

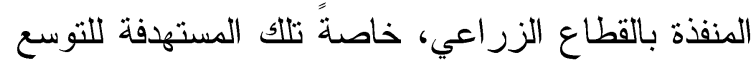

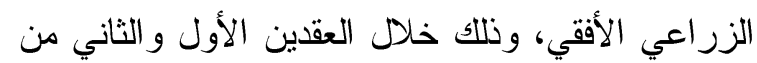

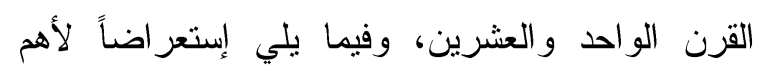
النتائج التي تم التوصل إليها باستخدام البيانات الواردة ولنئ بالجدول (7) - (7).

(1) بدر اسة حجم العمالة الزراعية في مصر خلال.

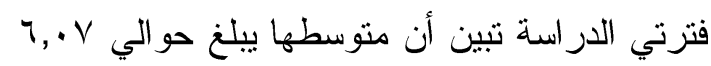

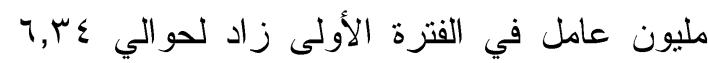
مليون عامل خلال الفترة الثانية، بمعدل قدر بنحو

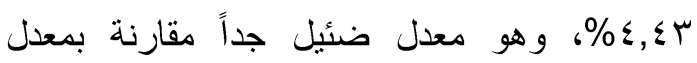

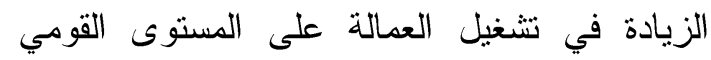

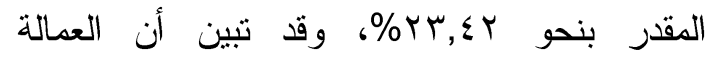
الزراعية في مصر تزيد بمعدل سنوي قدر بنحو

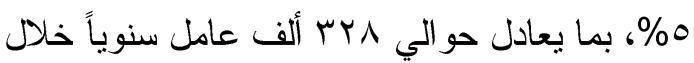
الفترة الأولى، ولكنها انخفضت بمعدل سنوي قدر 


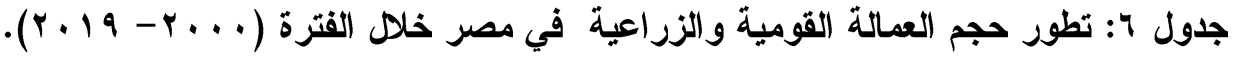

\begin{tabular}{|c|c|c|c|c|}
\hline 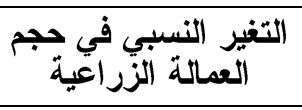 & مساهمة القطاع التزيلةاعي & الزجمراعية العما & إجمالي حجم & السنة \\
\hline$(\%)$ & $(\%)$ & (مليون عامل) & (مليون عامل) & \\
\hline & r & 0,1 . & $I V, Y$. & r... \\
\hline $1,79-$ & $r \wedge, 0 \leqslant$ & $0, \cdot 1$ & $1 v, 04$ & r.. \\
\hline $1,9 \%-$ & $r v, o r$ & $\{, q)$ & IV,AT & $r \ldots r$ \\
\hline $1 ., 1 \varepsilon$ & $r q, \wedge r$ & $0, \varepsilon 1$ & $1 \lambda, i r$ & $r \ldots r$ \\
\hline $1 \cdot, \cdot 1$ & 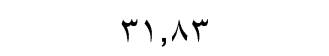 & 0,97 & $\mid \lambda, V Y$ & $r \ldots \varepsilon$ \\
\hline$r, .4$ & $r \cdot, q \varepsilon$ & $7, \cdot 1$ & 19,70 & r... \\
\hline $7,7 \mathrm{~V}$ & r, r & $7, \leqslant 9$ & $r \cdot, r V$ & r... \\
\hline$\lambda, \curlyvee \wedge$ & r ו,v & $V, \cdot r$ & rY,IY & $r \ldots r$ \\
\hline 1,00 & $r 1,79$ & $V, I T$ & $r r, 0)$ & $r \ldots \Lambda$ \\
\hline$r, 0 .-$ & $r 9,97$ & $ד, \Lambda \Lambda$ & $r r, q \Lambda$ & $r \ldots q$ \\
\hline r, l. - & $r \lambda, r \Lambda$ & $7, V \leqslant$ & $r r, \lambda r$ & r.l. \\
\hline- & $r \cdot, \cdot \Lambda$ & $7, \cdot V$ & $r \cdot, I Y$ & المتوسط السنوي للفترة الأولى \\
\hline- & $" 1,0$ & $" 0$ & "T, Tr & معدل التغير (\%) \\
\hline $1, r$. &.,$\ldots 0$ & $\cdot, \Gamma Y \Lambda$ & & $r \cdot 11$ \\
\hline ד & $r q, r \leqslant$ & ז ז, & $r$ rero & r.IT \\
\hline$\varepsilon, q \varepsilon$ & $r v, \cdot v$ & 7, ז & . ד, & $r .1 T$ \\
\hline 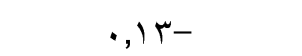 & $r v, 9 T$ & $r, \mathrm{r}$. & $r$ r, qY & r.ls \\
\hline$\varepsilon, \varepsilon \%-$ & $r v, \infty$ & 7,79 & $r \varepsilon, r$. & $r .10$ \\
\hline $1, r \varepsilon$ & ro, $\mathrm{Ar}$ & T. . & $r \varepsilon, \mathrm{v} \wedge$ & $r .17$ \\
\hline$\cdot, 01$ & ro,or & $ד, \sum \wedge$ & ro,rr & r.IV \\
\hline Ir, $\{\lambda-$ & ro,.0 & 7,01 & $r \uparrow, \cdot \cdot 1$ & $r \cdot 1 \Lambda$ \\
\hline$\varepsilon, \varepsilon r-$ & ז'ו & $0,1 \varepsilon$ & $r, \cdot r$ & $r .19$ \\
\hline- & $r 0, \varepsilon V$ & $7, \Gamma \varepsilon$ & $r \varepsilon, \lambda r$ & المتوسط السنوي للفترة الثانية \\
\hline- & "r r,q- & ${ }^{*} r, \xi-$ & "1,4 & معدل التغبر السنوي (\%) \\
\hline
\end{tabular}

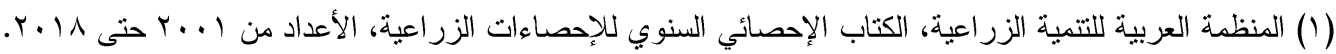
(Y) (Yموعة البنك الدولى، الإحصاءات المالية اللولية، مؤشر الات التتمية العالمية، ملفات البيانات.

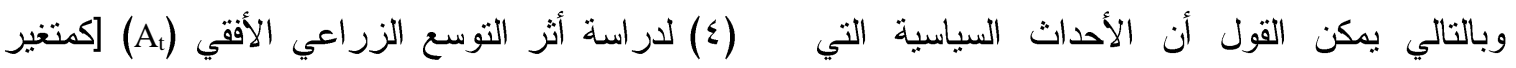
مسنقل] على تشغيل العمالة الزراعية (Labt)

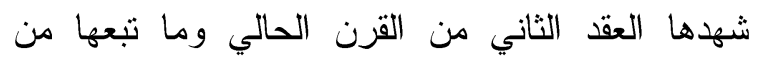
[كمتغير تابع] تم تقدير نماذج الإنحدار البسيط و التي التي

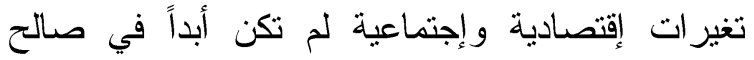

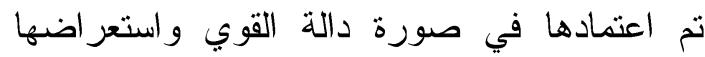
بصورتها النحويلية [الذطية]، وذلك بعد أن تم التأكد

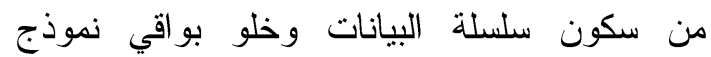

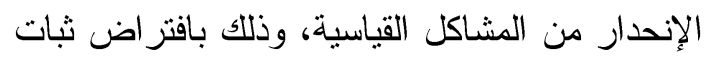

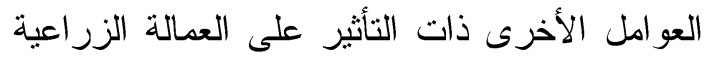

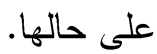
العمالة الزراعية، الأمر الذي يدعو لإعادة النظر في لئي مجموعة الإجراءات والسياسات التي من شأنها إعادة

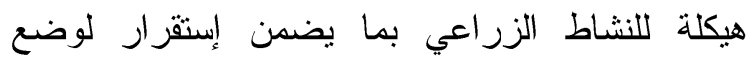
العمالة الزراعية والإستفادة منها خاصةً العمالة الماهرة منها، وذلك في ظل التحديات التي قد تقابلها مصر فيما

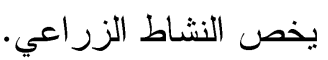


تشغيل تلك العمالة بنحو ؟Y,\%، مما يعني أن هذه المشروعات اعتمدت بصفة رئيسية على تكثيف رأس المال واستخدام التكنولوجيا على حساب نتغيل العمالة. ومن هنا يمكن القول أن البرامج التي تم تتفيذها في إطار تحقيق التنمية بالقطاع الزراعي أغفلت الجوانب البرات

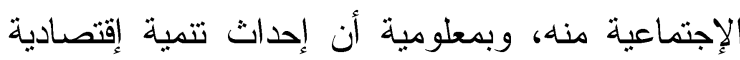
لابد معه الأخذ في الإعتبار إحداث نمو منوازن

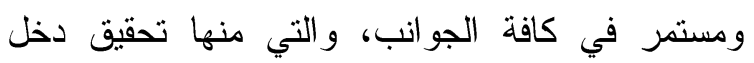
مناسب ومستقر للعاملين بالقطاع الزراعي، وهو الأمر ولئر

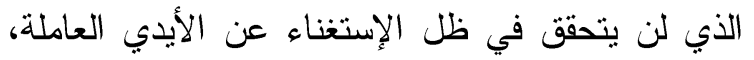
أي أن تحقيق تتمية إقتصادية في هذا القطاع الحيوي لإني

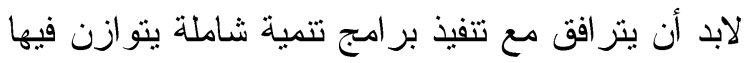

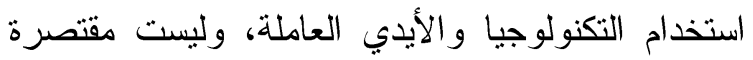

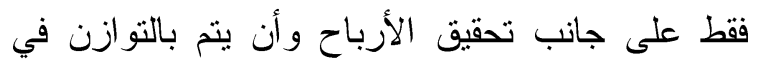

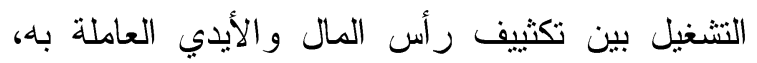
ومن نافلة القول أن إستمرار إغفال هذا الجانب

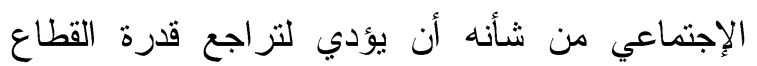

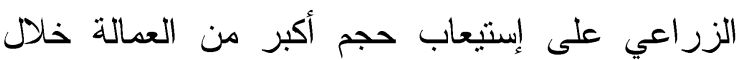

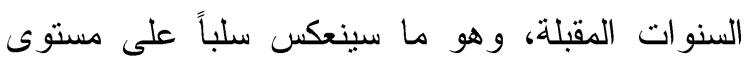
المقتصد الزر اعي و المقتصد القومي على حد سو اء.

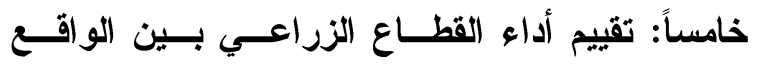

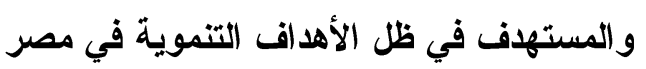
في هذا الجزء من البحث سيتم تقييم أداء القطاع الزر اعي من حيث قدرته على تحقيق الأهداف المنشودة منه للمساهمة في تحقيق تتمية إقتصادية مستدامة و إحداث نمواً إقتصادياً له إنعكاسات إجتماعية منشودة، وذلك بالأخذ في الإعتبار أبرز التغيرات التاريخية لمؤشرات الأداء التي نم دراستها بهذا البحث، وذللك الإنات

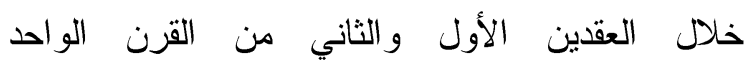

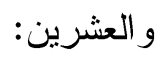

(1) فيما يخص قطاع التجارة الخارجية فقد اسهتدفت

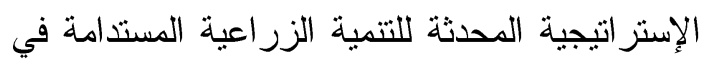

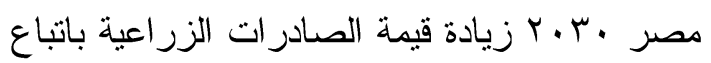
عدة إجراءات تعمل على تدعيم القدرة التتافسية
(أ) الصورة الدالية التالية تبين التأثير المعنوي الإيجابي

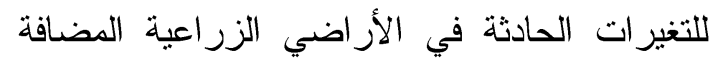
بالإستصلاح على تشغيل العمالة الزراعية في الفترة الأولى من الدراسة، حيث تبين أن تغير اً في المساحة

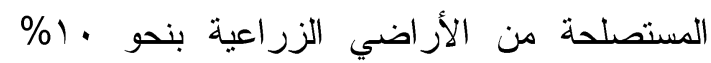
يتبعه تغيراً في نفس الإتجاه يقدر بنحو 90، • \% عدد العاملين بالقطاع الزر اعي، وهو ما اتضح جلياً وعلى نحو ملحوظ من زيادة ملحوظة في عدد العاملين بالقطاع الزراعي بالتزامن بين مشروعات التوسع الأفقي المنفذة في تلك الفترة. Ln Lab ${ }_{1 t}=\ln 4.340+0.095 \operatorname{InA}_{1 t}$

$$
(6.539)^{* * *}(2.193)^{* * * *}
$$

$\mathrm{R}^{2}=0.35 \quad \mathrm{~F}=(4.810)^{* * * *}$

(ب) الصورة الدالية التالية تبين التأثير المعنوي للتغيرات

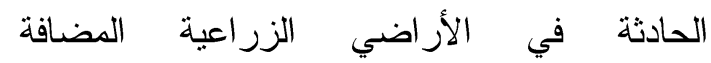
بالإستصلاح على تشغيل العمالة الزر اعية في الفترة الثانية من الدراسة ولكن على عكس ما حدث خلال

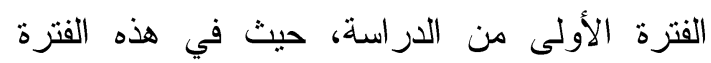
تحقق تغيراً عكس الإتجاه في تشغيل العمالة

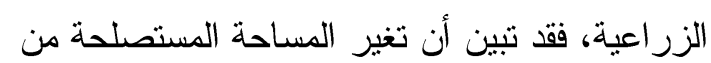

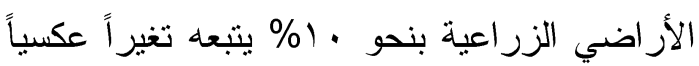

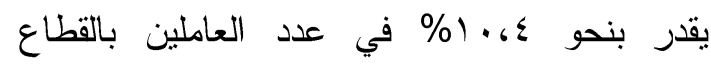
$\mathrm{Ln} \mathrm{Lab}_{1 t}=\ln 9.105-0.104 \mathrm{InA}_{2 t}$

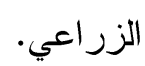
$\mathrm{R}^{2}=0.73 \quad \mathrm{~F}=(18.72)^{* *}$ من التحليل السابق لنموذجي الإنحدار تبين أن

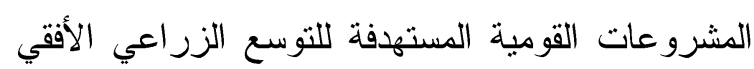
خلال العقد الأول من القرن الحالي جاءت في صالح

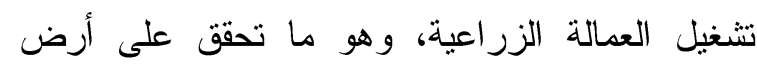

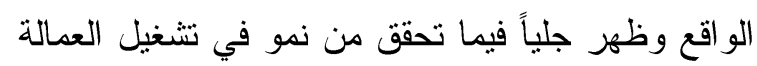

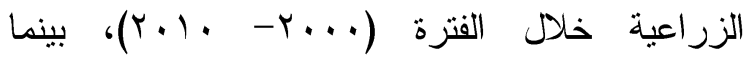
مشروعات التوسع الزراعي الأفقي المنفذة خلال الفترة

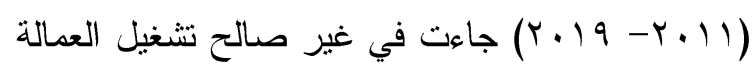
الزراعية، حيث شهدت تلك الفترة تز اجعاً وتتاقصاً في 
يتطلب إعادة النظر فيما هو مستهدف لمساهمة للقطاع الزر اعي في الناتج المحلي.

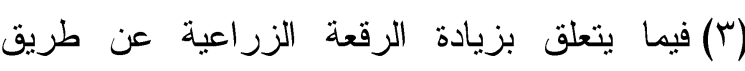

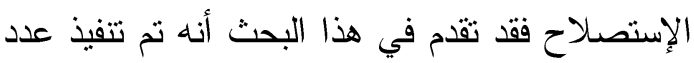

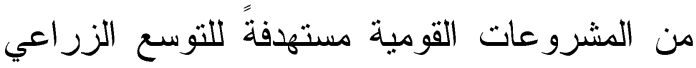
الأفقي ومنها تبين أن إجمالي المساحة المستهدف

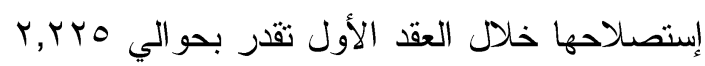

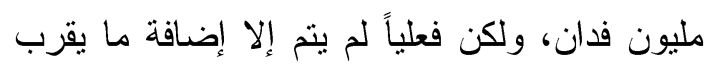
من عه, • مليون فدان فقط خلال العقد الأول تمثل فئل

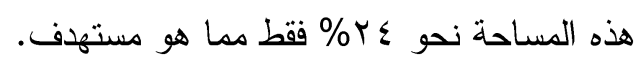
بينما استهدفت الإستر اتيجية المعدلة للتتمية الزر اعية

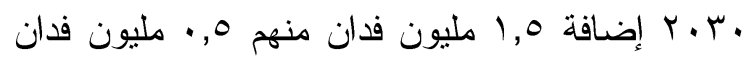

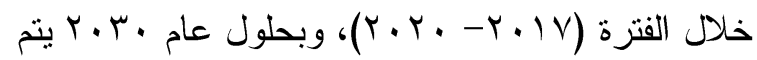

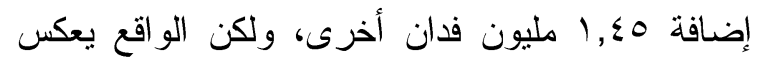
غير ذللك، فوفقاً للبيانات الواردة بالجدول (0) فقد تبين

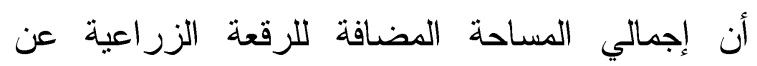

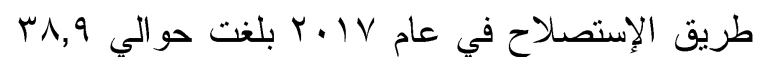
ألف فدان ثم أضيف في الأعوام الثلاثة الثالية مساحة

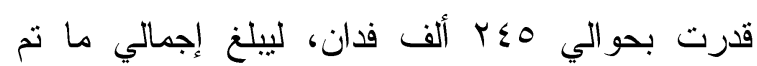

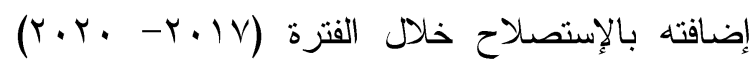

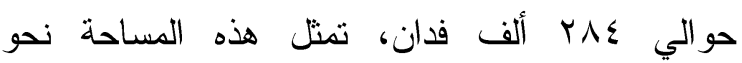
1,人 \% من المساحة المستهدف إضافتها.

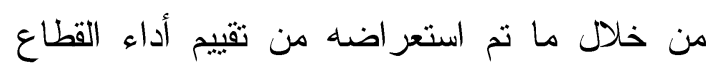
الزراعي بين الواقع و المستهدف فيما يخص زئن زيادة الرقعة الزراعية بالإستصلاح تبين وجود فجوة كبيرة

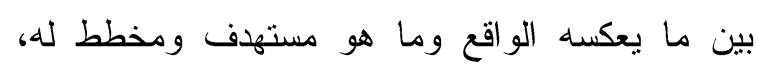

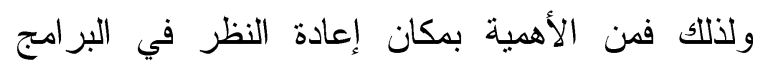
التنفيذية الني ينت من خلالها تحقيق الأهداف المنشودة، النفية ومحاولة عرقلة العوامل المثبطة لتحقيق ثلك الأهداف،

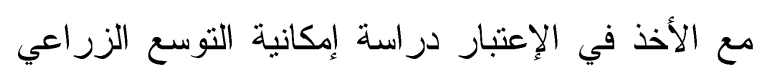
الأفقي في ظل الأزمة المرتقبة في حصة مصر من مياه النيل بعد بدء المرحلة التالية لملء سد النهضة بأنثيو بليا.
للمنتجات الزر اعية في الأسوق الدولية(10) حيث من

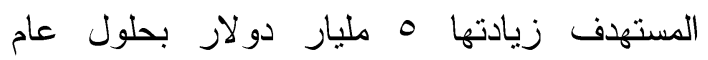

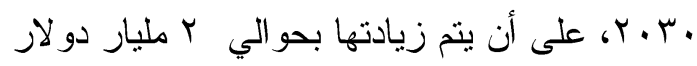

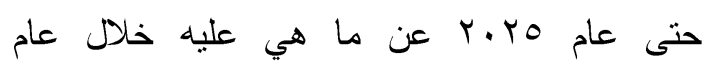

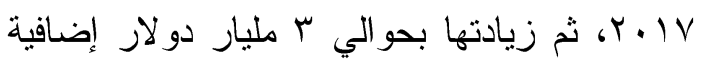

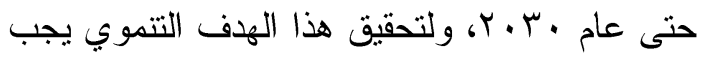

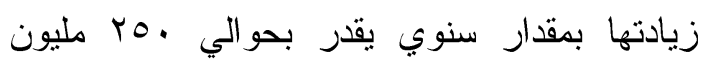

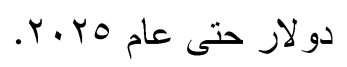

ولكن البيانات الواردة بالجدول (1) بالملحق توضح

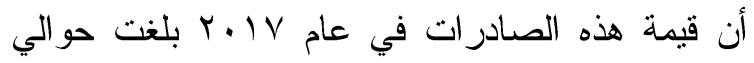

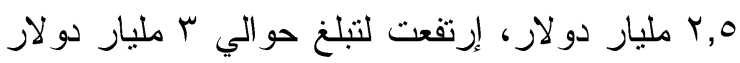

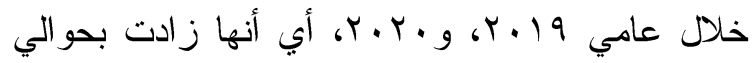
مليون دولار فقط خلال ثلاث سنوات بمعدل

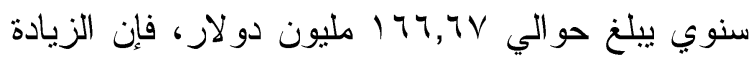

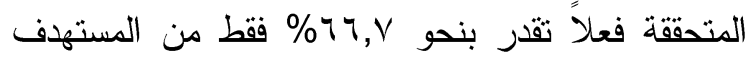
خلال هذه السنوات الثلاثة، و إذا ظلت معدلات الزيادة

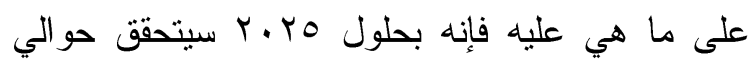

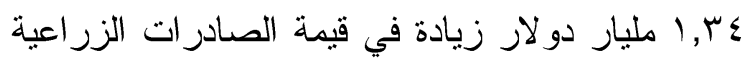

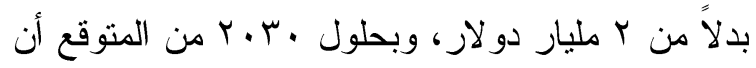

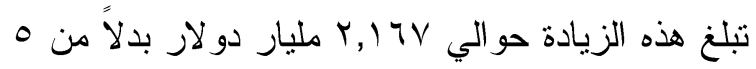

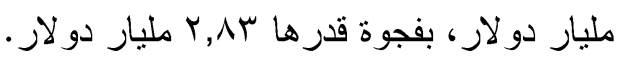

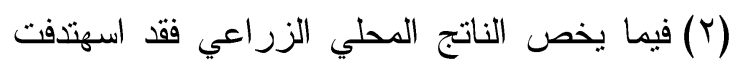
الإستر اتيجية زيادة نسبة مساهمة القطاع الزراعي

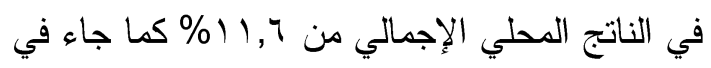

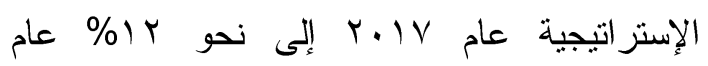

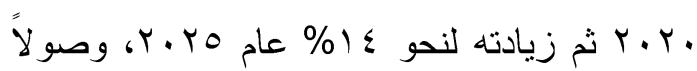
لنحو 10\% عام .r.Y.r، وقد تحقق هذا الهدف

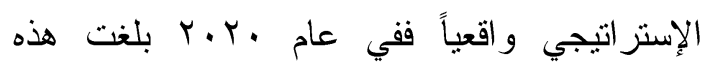

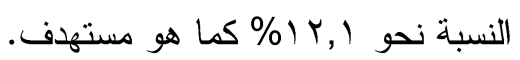

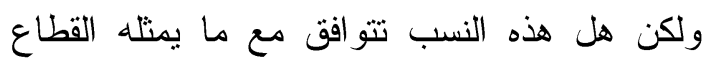

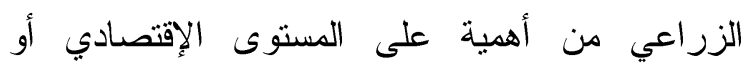
الإجتماعي، خاصةً في ظل إزدياد سكاني يتطلب تأمين

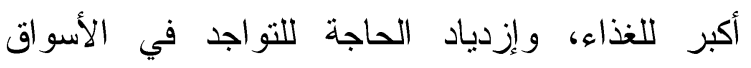

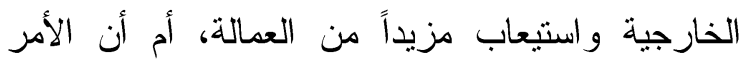


توشكى البادرة الأولى للتنمية الثشاملة بجنوب الــوادى،

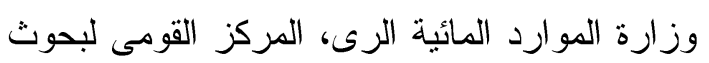

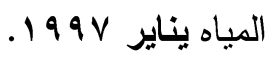

سعد زكي نصار، بعض القضايا المعاصرة في السياسة

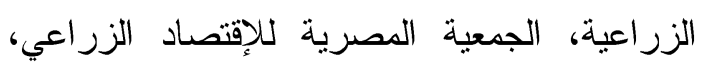

$$
\text { .r. r. }
$$

السيد محمود الثرقاوى، رؤى نقدية بحثية فى مجــال

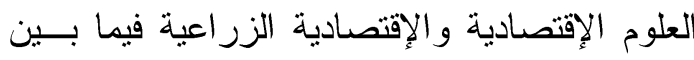

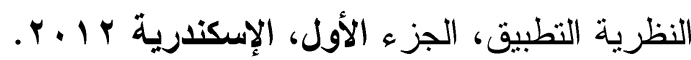
السيد محمود الثرقاوى، رؤى نقدية بحثية فى مجــال

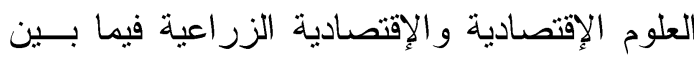

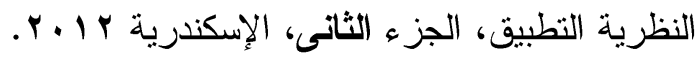
صالح العصفور، الأرقام القياسية، سلسلة جسر التتمية،

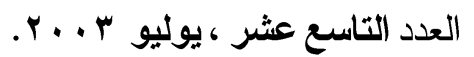
عبد القادر محمد عبد القادر، الحـديث فـــي الإقتصـــاد

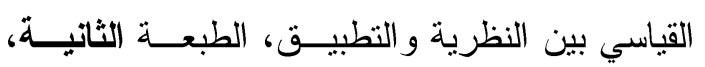

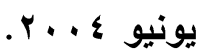

عبد القادر محمد عبد القادر، طرق قئـاس العلاقــات الإقتصادية، دار الجامعات المصرية، .99 19.

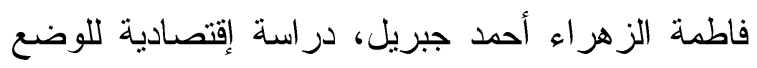

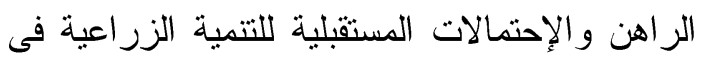
المقتصد المصرى، رسالة دكتور اة، قسم الاقتصاد

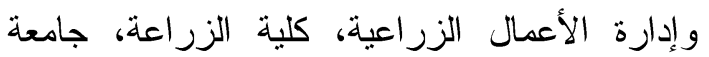

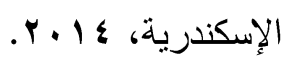

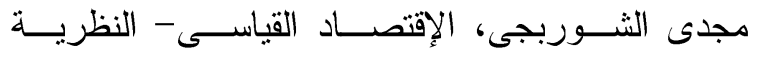

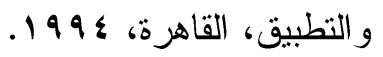

الهيئة العامة لمشروعات التعمير و التتميــة الزر اعيـة،

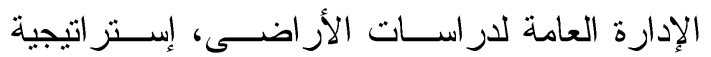
التوسع الأفقى فى إستصلاح الأر اضى حتـى عـى عـام .$r \cdot I V$

وزارة الزراعة وإستصلاح الأراضى، الإستراتيجية

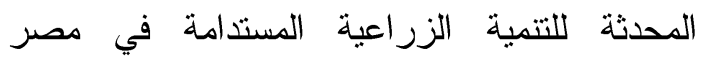
.r. 19 , r.r.
(ع) فيما يخص تقيبم أداء القطاع الزراعي بين الواقع و المستهدف من حيث نتشيل العمالة فقد استهدفت

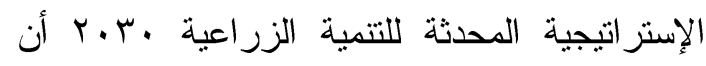
يشارك القطاع الزر اعي باستيعاب rV من من العمالة

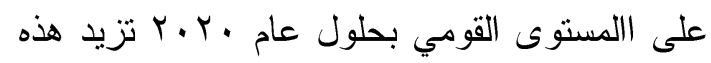

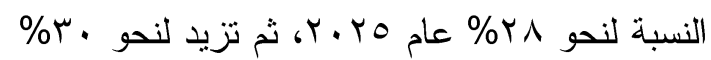
بحلول عام •r.r.r، ولكن الواقع يعكس تراجعاً و اضحاً في قدرة القطاع الزراعي على إستيعابه

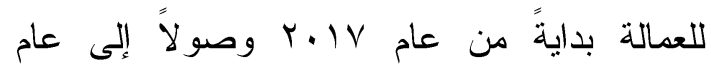

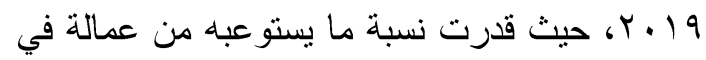

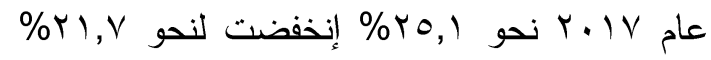

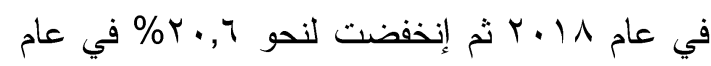

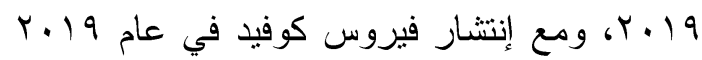
من المنتظر أن تتخفض هذه النسبة عن ما هي عليه

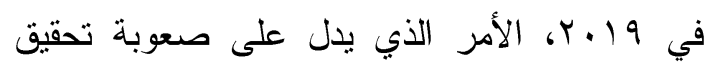

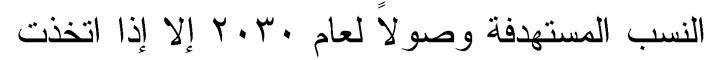
مجموعة من الإجر اءات غير التقليدية التي من شأنها زيادة قدرة القطاع الزر اعي على إستيعاب مزيداً من من الاجن

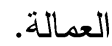
ومن نافلة القول أن القطاع الزراعي أصبح قطاعاً

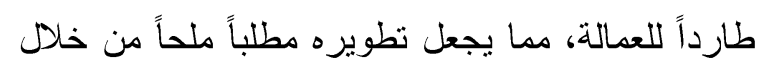

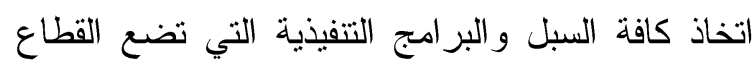

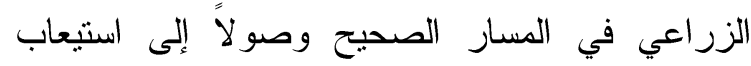

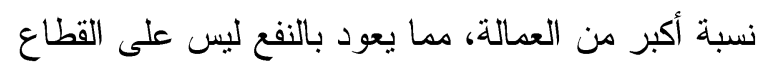

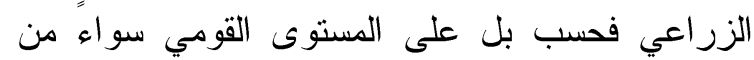
الناحية الإقتصادية أو الإجتماعية أو كلاهما معاً.

\section{المراجع}

أحمد صقر عاثور، التتمية وقضايا الحوكمة والإصلاح

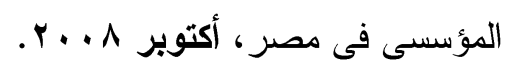
أحمد قدرى مختار محمد بهلول، الآثار المتوقعة للأزمة

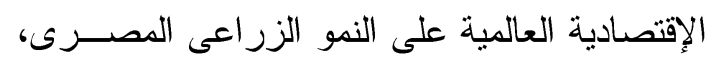

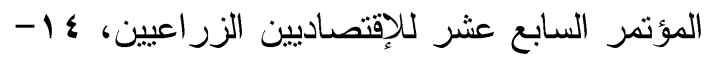

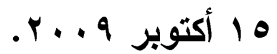




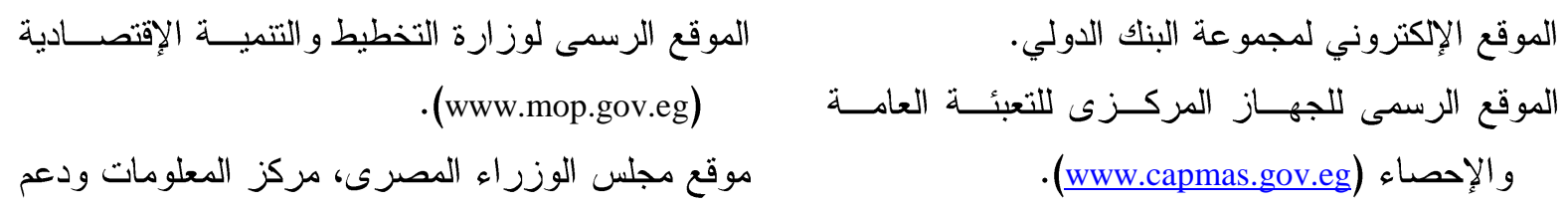

إتخاذ القرار (www.idsc.gov.eg)

\title{
Economic Study of the Performance of Egypt's Agricultural Sector in the Face of Contemporary Challenges
}

\author{
Fatma Elzahraa Ahmed gerbil \\ Agricultural Economics Research Institute - Agricultural Research Centre
}

\begin{abstract}
In the light of the research problem, the main objective of this research is to determine the extent to which the agricultural sector is able to fulfil its role in the development of the Egyptian economy and to assess its performance in the light of contemporary local and regional changes during the first and second decades of the twenty-first century by examining a set of sub-objectives.

The research has produced a series of findings, the most important of which are: The agricultural sector has contributed to reducing the economic burden on the Egyptian economy during the second decade of the present century in terms of its contribution to foreign trade. It was also found that the exchange rate increased in favour of exports and imports, as well as that the agricultural sector declined in its role in the national economy in terms of its contribution to GDP, suffered from periods of contraction in the size of its economic activity affected by some economic decisions made in the Egyptian economy, as well as some political changes that were not matched by economic changes.

The research also found that the rate of utilization of the agricultural area unit in Egypt declined during the two study periods. The research also showed that the political events of the second decade of the present century and the subsequent economic and social changes were never in favour of agricultural employment.

It has also been shown that the agricultural sector has become a volatile employment sector and that its aim in absorbing more employment must go hand in hand with the implementation of comprehensive development programmes that balance the use of technology and labour, and that the continued omission of this social aspect will lead to a decline in the ability of the agricultural sector to absorb more labour in the coming years, which will have a negative impact on the national level.

An assessment of the performance of the agricultural sector between reality and target shows that about $66.7 \%$ of the targeted increase in the value of Egyptian agricultural exports over the period was achieved. (2017- 2020) A gap of $\$ 2.83$ billion in this value is expected by the year 2030, as shown by the achievement of the target for the contribution of the agricultural sector to GDP, as well as a significant gap between the reality and the planned increase in the agricultural area by rehabilitation where about 56 have been achieved,8\% of the target increase up to 2020 , as shown by the difficulty of achieving the agricultural sector's employment absorption targets. $1 \%$ dropped to about $21.7 \%$ in 2018 and then decreased to about $20.0 \% .6 \%$ in 2019, and with the spread of Covid virus in 2019, this proportion is expected to fall short.

On the basis of the findings, the research recommended a review of the set of actions and policies that would restructure agricultural activity, which would increase the contribution of the agricultural sector to GDP, especially in view of the many challenges that might hamper agricultural activity, and a study of the possibilities for horizontal agricultural expansion in the light of the anticipated crisis in Egypt's share of the Nile waters after the next phase to fill the Zabia renaissance dam. The research also recommends that operational programmes should be reviewed to promote economic development in the agricultural sector, with comprehensive development programmes that balance the use of technology and labour so as to stabilize the situation of agricultural labour, especially skilled labour, and to impede the inhibitors to achieve the objectives of the agricultural sector.
\end{abstract}




\section{الملحقات}

جدول ا: تطور سعر الصرف، وإجمالي حجم التجارة الخارجية، والميزان التجاري الإجمالي خلال الفترة (... بـ $\cdot(r \cdot r$.

\begin{tabular}{|c|c|c|c|c|c|}
\hline قيمة العجز في الميزان & قالّمة إجماتي & قالصادرة إجماتي & التجارة ألخارجية & سعر الصرف & السنة \\
\hline (مليار جنيه) & (مليار جنيه) & (مليار جنيه) & (مليار جنيه) & (جنيه/دولار) & \\
\hline rY,YqS & $\leqslant \Lambda, 70$ & $17, r 01$ & $70, \ldots$ & $r, \S)$ & $r \ldots$ \\
\hline$r \varepsilon, 1 \uparrow 1$ & $0 ., 709$ & $\mid 7, \leqslant 91$ & $T V, 10$ & $r, T V$ & $r \ldots l$ \\
\hline TO, TrV & OT,乏AY & $r 1,1 \leqslant 0$ & $V V, T r$ & $\varepsilon, r$ & $r \ldots r$ \\
\hline$r \wedge, Y V)$ & ro, & r & $1.1,9$. & $0, \cdot r$ & $r \ldots r$ \\
\hline N & $\vee 9, \vee 17$ & $\varepsilon \vee, T \vee \wedge$ & IrV,rq & 7,19 & r.. \\
\hline rT, & $11 \varepsilon, 7 \wedge \wedge$ & סצוT, & $|\vee \neg, r|$ & $0, V \wedge$ & r... \\
\hline$r 9,0 \cdot 1$ & $\| \wedge, r V r$ & $\vee \wedge, \wedge T \leq$ & $19 V, r \varepsilon$ & $0, V r$ & $r \ldots r$ \\
\hline سז,וד & $104,0 \wedge 4$ & 91, Y07 & $r \leqslant r, \wedge \varepsilon$ & $0,1 \leqslant$ & $r \ldots v$ \\
\hline$|\varepsilon \varepsilon, 7| \vee$ & YAV,VYE & $1 \leq r, 1 \cdot V$ & \&T., & $0, \varepsilon r$ & $r \ldots \Lambda$ \\
\hline $110, r \wedge r$ & $r \leq 9,971$ & Tा & $\Gamma_{\wedge} \varepsilon, \infty 0$ & $0,0 \leqslant$ & $r \ldots q$ \\
\hline $1 \leq 0,011$ & r.., & $10 \leqslant, 10$ & $\{00, r)$ & $0, \pi T$ & $r .1$. \\
\hline 70,091 & $|r \Lambda, 0 V|$ & $V Y, q \vee q$ & $r 11,00$ & $0,1 Y$ & المتوسط السنوي \\
\hline $1 \wedge r, .9 \varepsilon$ & $r V I, \leqslant \leqslant 0$ & $|\wedge \Lambda, r O|$ & $009, \wedge$. & 0,94 & $r \cdot 11$ \\
\hline$Y 00,1 \wedge V$ & & $1 V \wedge, 01 Y$ & $M|r, r|$ & $7, \cdot 7$ & $r \cdot I r$ \\
\hline 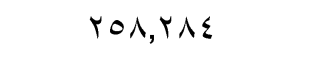 & $\leqslant 00,991$ & $19 V, V \mid \leq$ & ror,vi & $\uparrow, \wedge \vee$ & $r \cdot 1 r$ \\
\hline r & & $190, Y \vee 4$ & $\vee \backslash \wedge, V 4$ & $v, \cdot \lambda$ & $r \cdot 1 \leqslant$ \\
\hline$\{.0,74$ & OY & I IT,ror & VTr,IV & $v, 79$ & $r .10$ \\
\hline$\varepsilon \vee V, q \vee$ & $V \cdot \wedge, Y \wedge q$ & (r., & $9 \leftrightarrow \wedge, 7)$ & $1 \cdot, \cdot r$ & $r .17$ \\
\hline VYO, V9० & $1118, .79$ & $\leq \pi), Y \vee \varepsilon$ & $17 \leqslant \wedge, \Gamma \leqslant$ & $V, V V$ & $r \cdot I V$ \\
\hline 9$) 7,9 \leqslant Y$ & $1 \leqslant r q, \cdot 19$ & OYY, .VY & $1971,1$. & $1 v, v q$ & $r \cdot 11$ \\
\hline$V E Y, V Y T$ & IrrV, & $\leqslant 9 \leqslant, V \leqslant$ & IVTr,Y. & $17, r 9$ & $r .19$ \\
\hline MVV,ONO & YAV, TYY & $r .9, v \varepsilon$ & $99 \vee, .7$ & $10, \lambda r$ & $r \cdot r$. \\
\hline$\varepsilon 7 V, 1 \leq \varepsilon \lambda$ & $V(1, Y V \cdot 1$ & rq\&, Iror & $1.00, \varepsilon$. & $11,1 \leq$ & المتوسط السنوي \\
\hline
\end{tabular}

المصدر - جمعت وحسبت من: (1) الجهاز المركزي للتعبئة العامة والإحصاء، الكتاب الإحصائي السنوي، نشرة النجارة الخارجية خلال

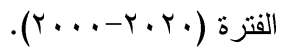


جدول r: تطور الناتج المحلي الإجمالي، والناتج المحلي الزراعي بالقيم الجارية وبالمليار جنيه، والرقم القياسي

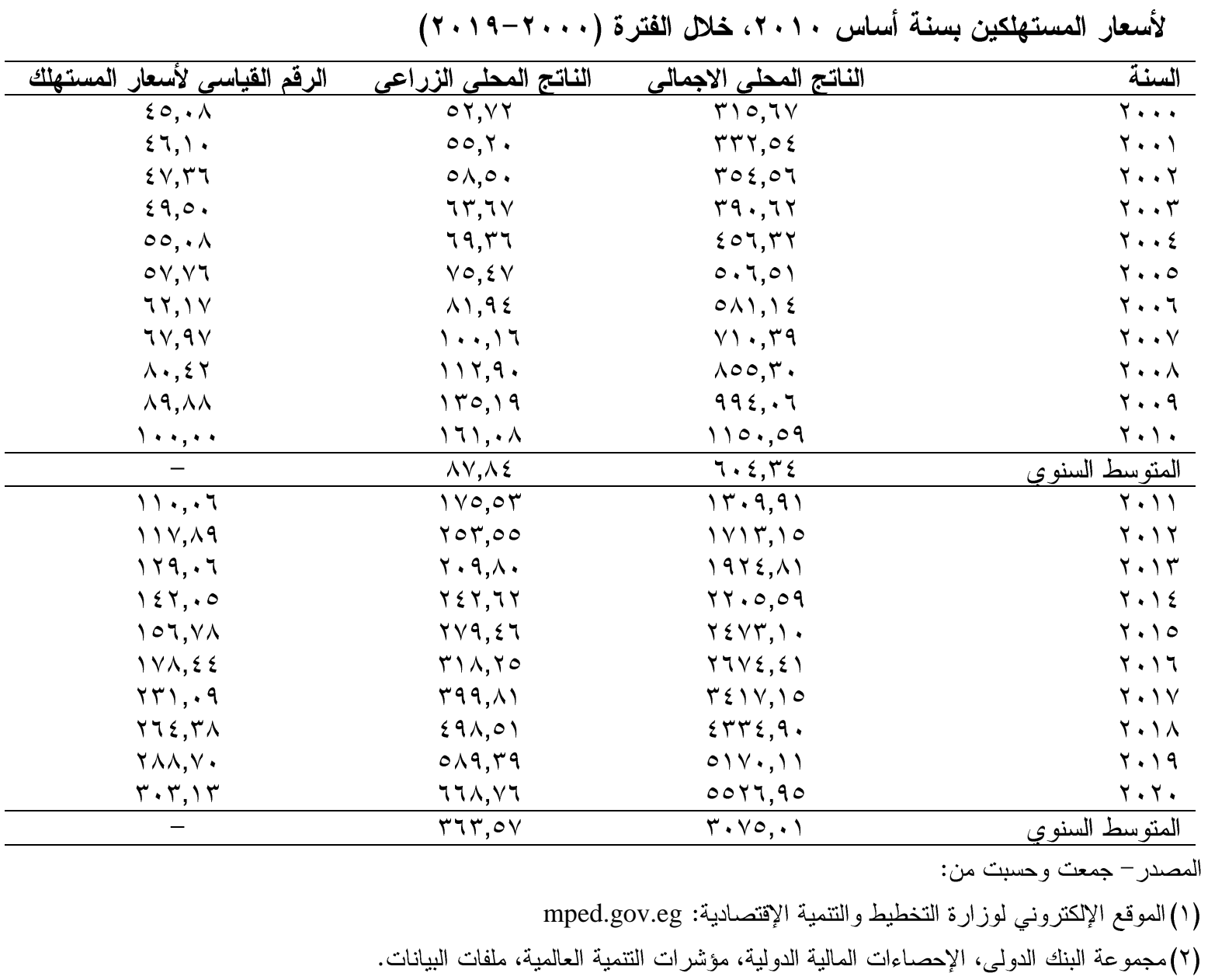

